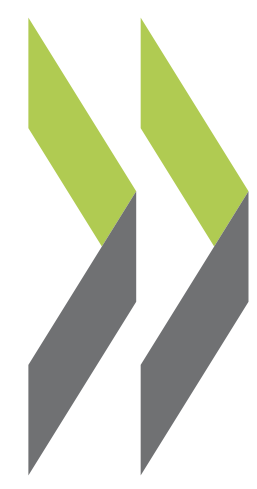

OECD Science, Technology and Industry Working Papers $2020 / 02$

Patterns of innovation, advanced technology use and business practices in Canadian firms
Fernando GalindoRueda,

Fabien Verger, Sylvain Ouellet 
Note to Delegations:

This document is also available on O.N.E Members and Partners under the reference code:

\section{DSTI/STP/NESTI(2018)4/FINAL}

OECD Working Papers should not be reported as representing the official views of the OECD or of its member countries. The opinions expressed and arguments employed are those of the authors. Working Papers describe preliminary results or research in progress by the author(s) and are published to stimulate discussion on a broad range of issues on which the OECD works. Comments on Working Papers are welcomed, and may be sent to the Directorate of Science, Technology and Innovation, OECD, 2 rue André-Pascal, 75775 Paris Cedex 16, France.

This publication is a contribution to the OECD Going Digital project, which aims to provide policymakers with the tools they need to help their economies and societies prosper in an increasingly digital and data-driven world.

For more information, visit www.oecd.org/going-digital.

\#GoingDigital

This document, as well as any data and map included herein, are without prejudice to the status of or sovereignty over any territory, to the delimitation of international frontiers and boundaries and to the name of any territory, city or area.

(C) $\operatorname{OECD}(2020)$

You can copy, download or print OECD content for your own use, and you can include excerpts from OECD publications, databases and multimedia products in your own documents, presentations, blogs, websites and teaching materials, provided that suitable acknowledgment of OECD as source and copyright owner is given. All requests for commercial use and translation rights should be submitted to rights@oecd.org. 


\section{Table of Contents}

Patterns of innovation, advanced technology use and business practices in Canadian firms ........ 5

Abstract.......

Executive summary …................................................................................................................................. 6

1. Introduction ................................................................................................................................................. 8

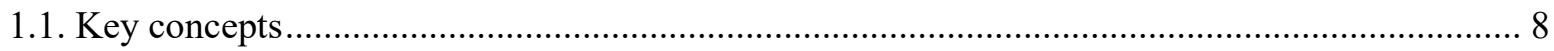

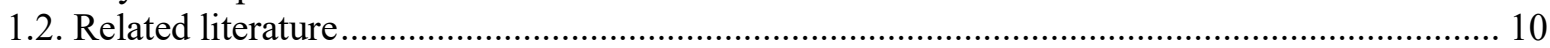

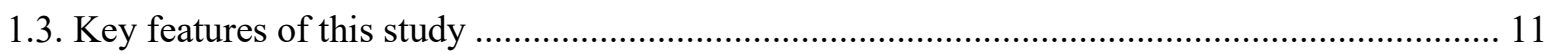

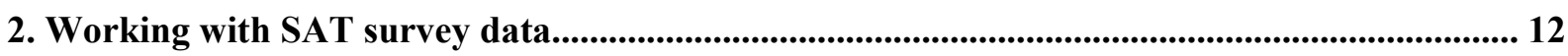

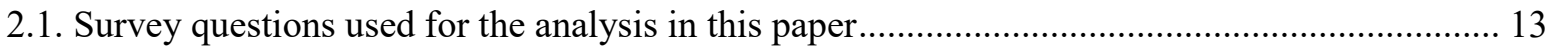

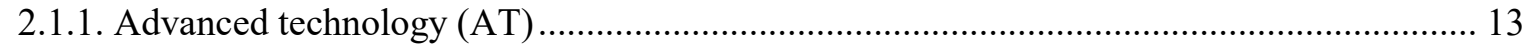

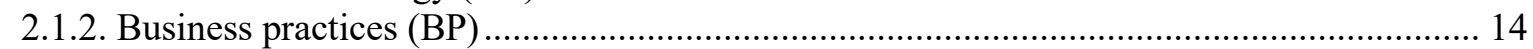

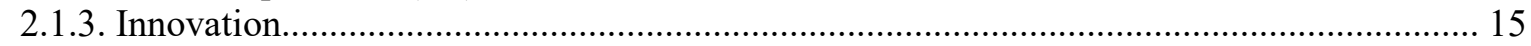

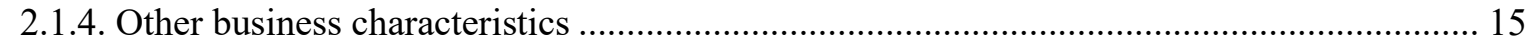

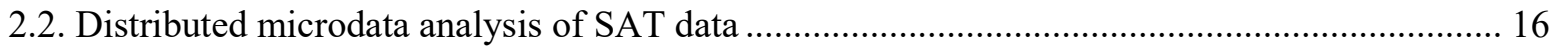

3. Understanding patterns of technology and business practice usage............................................... 16

3.1. Making sense of the multidimensional ATBP data .............................................................. 16

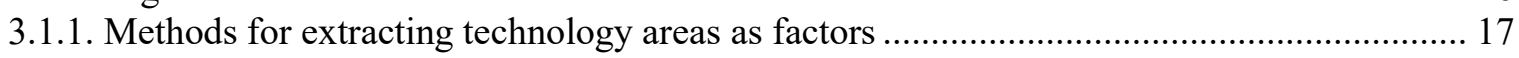

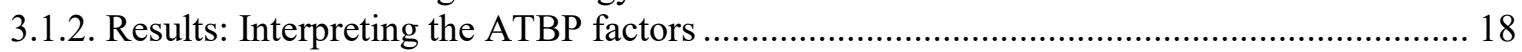

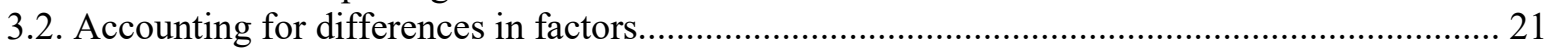

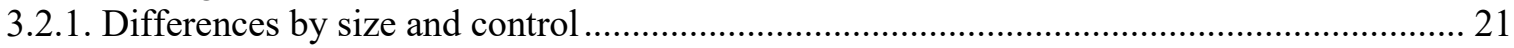

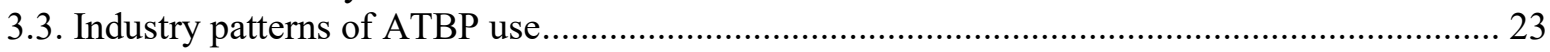

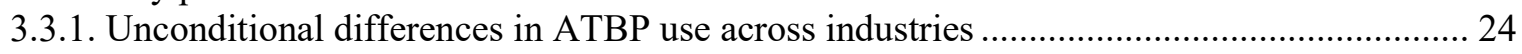

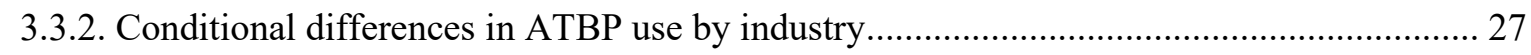

4. Technology usage, business practices and innovation.......................................................................... 28

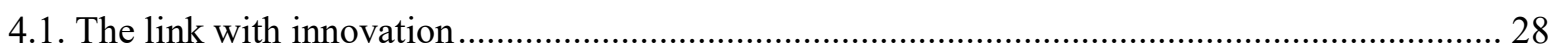

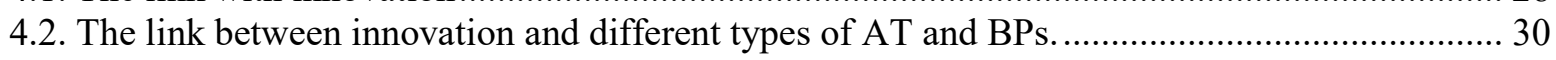

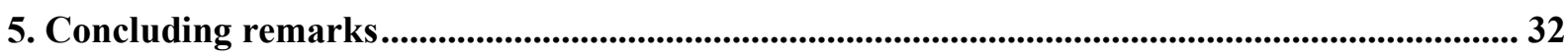

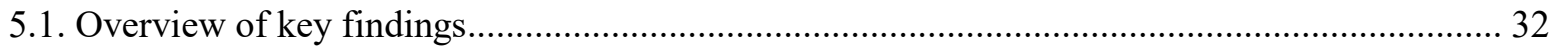

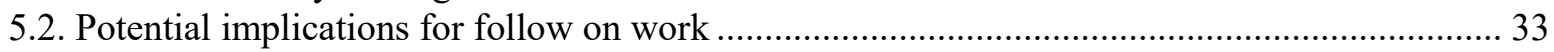

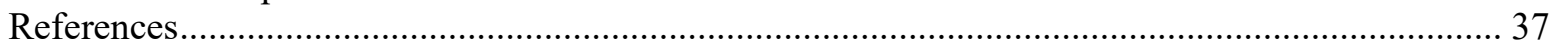

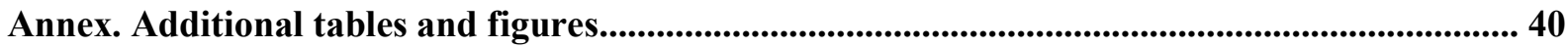

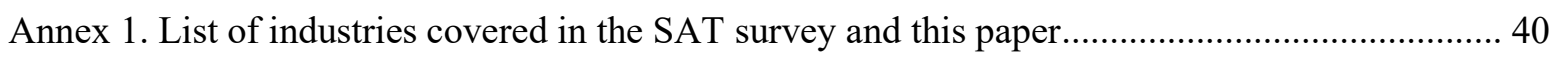

Annex 2. List of advanced technologies and business practices used in this paper........................... 41

Annex 3a. Adoption rates of technologies and business practices ................................................ 43

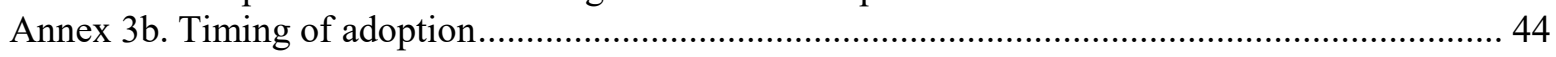

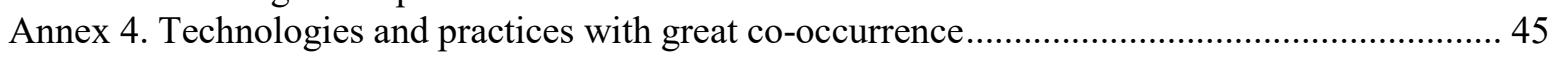

Annex 5. Large firms' use of technologies compared to small firms .................................................. 46

Annex 6. Industry characteristics based on regression-adjusted industry coefficients for factor

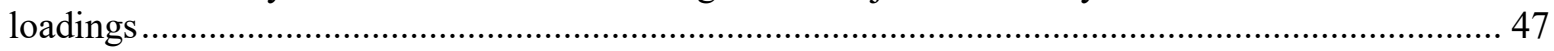




\section{Tables}

Table 1. Factor loadings for advanced technologies and business practices (ATBPs) ......................... 18

Table 2. Technology usage, practice usage and business characteristics ............................................. 22

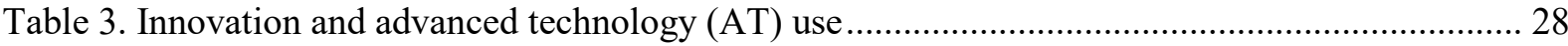

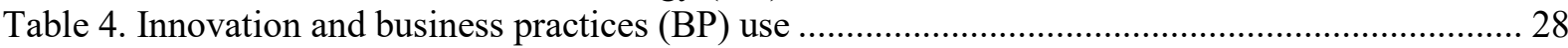

Table 5. Innovation explained by technology and business practice usage .......................................... 29

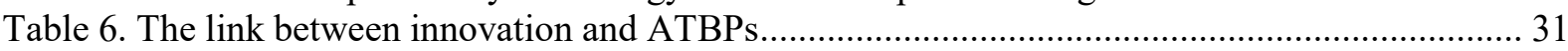

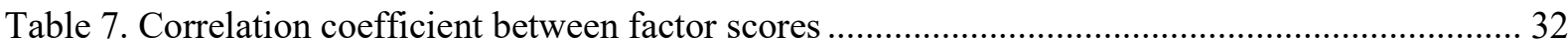

\section{Figures}

Figure 1. Technology, business practices and innovation 9

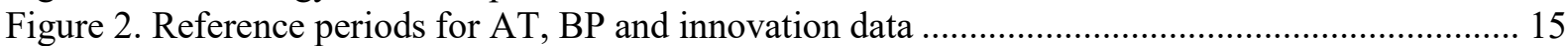

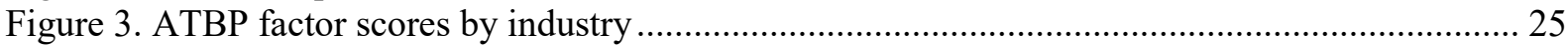




\title{
Patterns of innovation, advanced technology use and business practices in Canadian firms
}

Fernando Galindo-Rueda*, Fabien Verger* and Sylvain Ouellet+

\begin{abstract}
This paper uses a distributed microdata analysis approach to map patterns of technology adoption in Canadian firms, exploring the relationship between technology adoption, business practices and innovation. Prepared by the OECD NESTI secretariat in collaboration with Statistics Canada, the paper leverages a unique enterprise database combining information on innovation, technology adoption and the use of selected business practices. This work suggests a number of possible pathways for selecting and defining priority technology and business practices for data collection and reporting, implementing recommendations in the 2018 Oslo Manual on enablers and objectives of business innovation, and identifying potential synergies between business innovation, management and ICT, and other surveys focused on various aspects of technology adoption.
\end{abstract}

(*) OECD Directorate for Science, Technology and Innovation (STI), Science and Technology Policy Division (STP)

(+) Statistics Canada 


\section{Executive summary}

This document reports on the results of work by the OECD's Working Party of National Experts on Science and Technology Indicators (NESTI) on the measurement and analysis of business innovation, as part of the Programme of Work and Budget of the OECD Committee for Scientific and Technological Policy. A collaboration between the OECD and Statistics Canada has explored the use of Advanced Technologies and Business Practices (ATBPs) and their link with innovation performance, based on firm-level microdata from Canada's Survey of Advanced Technology (SAT 2014).

The analysis of this unique, integrated data source, combining information on technology development, use and innovation performance, provides the basis for identifying complex patterns of ATBP adoption among Canadian firms, and for drawing lessons that may also be relevant elsewhere. The use of factor analysis as a data exploratory technique enables the examination of the rich content of the SAT microdata on the usage of 68 different ATBPs by a representative sample of nearly 8000 Canadian firms. It reveals seven overarching thematic areas of ATBP specialisation by firms: logistics software technologies; management practices and tools; automated production process technologies; geomatics and geospatial technologies; bio-and-environmental technologies; software and infrastructure as a service; and additive and micro manufacturing technologies. These thematic areas are strongly interrelated, especially "management practices and tools" with "logistics software technologies" and "automated production process technologies".

Profiles of how businesses use technology vary according to business' characteristics, namely (in this study) their size, country of control, and whether they outsource part of their activity. A robust positive relationship is found between technology adoption and firm size, although exceptions arise for technologies that appear to neutralise the effect of size when comparing firms within industries. This is the case of "additive and micro manufacturing technologies" and "software and infrastructure as a service". Both instances suggest that technology is not necessarily biased towards large firms and that the processes of digital transformation may allow for process improvements (on production and computing, respectively) that would have been unaffordable otherwise.

On average, foreign-controlled firms tend to be more intensive users of ATBPs than their domestic counterparts. The former use more logistics software technologies, management practices and tools, production process technologies and bio-and-environmental technologies than Canadian-controlled firms. On the contrary, they are less likely to use geomatics and geospatial technologies, for which domestic Canadian firms, for example in natural resource intensive industries, appear to find several applications. The business practice of outsourcing is positively associated with ATBP use, in particular with management practices and tools. For some technologies, this relationship depends on whether activities are outsourced within or outside Canada.

The study also proposes a classification of industries according to their technology use profile. Five groups of industries with distinctive ATBP intensities and patterns are identified. One is composed of ATBP-intensive manufacturing industries (e.g. the chemical and the computer industries) and is characterised by a high usage of "automated production process technologies" and "management practices and tools". The less ATBP-intensive manufacturing industries are classified in a separate group. In non-manufacturing sectors, industries that rely highly on logistics software technologies (most retail and wholesale 
industries) are grouped together. Industries intensively using geomatics and geospatial technologies (e.g. resource-based industries and transportation services) form another group. The remaining service industries are included in a low ATBP-intensive group. Grouping in this way reveals significant differences in ATBP usage between manufacturing and non-manufacturing industries. The results highlight how technology use variables, and their complementarity with commonly-used R\&D data, can help to build technology-based industry groupings. This is particularly the case in the service sector where many industries exhibit low levels of R\&D intensity while being characterised by high technology use intensity. This provides an additional argument for ceasing to characterise R\&D-intensity based classifications as "technology" measures without qualification.

The analysis shows a strong relationship between ATBP use and innovation, even after accounting for other factors. The odds of innovating are doubled when a firm reports using advanced technologies, and trebles when reporting the use of selected business practices. A refinement of the analysis by type of innovation shows that the use of advanced technologies is more closely related to the introduction of new business process (process innovation) than the delivery of new products (product innovation). On the contrary, for firms that develop technologies, innovation appears to be more oriented towards the introduction of new products. This suggests that on top of adapting their processes, many firms that develop technology commercialise products that incorporate those technologies or sell the technology as a product.

This paper's results are also indicative of a dynamic relationship between technology adoption and innovation. Using data on the timing of ATBP adoption in firms, it is possible to note that more recent ATBP adoption is more highly correlated with innovation than older implementation, confirming indeed that innovation indicators largely capture technology adoption and that technology adoption can be an enabler of innovation. Conversely, current innovation behaviour appears to be associated with plans among firms to implement ATBP in the near future.

In addition to the intrinsic interest in Canada's ATBP use and innovation patterns, these results can help motivate interest in the data among policymakers in a number of areas, for example in the context of the OECD's Going Digital project. Digital technologies do appear to have a widespread presence across several dimensions of innovation, but it is also important to avoid treating all types of technology adoption and innovation as pertaining to digital technologies or representing "technical" advances. This paper also provides an initial testing ground for implementing some of the recommendations arising from the latest edition of the Oslo Manual to better measure and interpret patterns and impacts of innovation and productive capabilities within firms. 


\section{Introduction}

Understanding how firms innovate and sustain productivity improvements is one of the main reasons for collecting and reporting statistical information on the innovation activities of firms. National innovation surveys collected under the guidance of the Oslo Manual framework (OECD/Eurostat, 2018) play a key role. The framework for measuring innovation has traditionally focused on capturing flow measures, i.e. measures of change. In its latest edition, the Oslo Manual draws attention to the importance of also capturing information on the underlying capabilities of firms. These capabilities may help them pursue innovations with higher chances of success, but may also directly influence their performance. Furthermore, reducing the analysis of innovation to the measure of flow activities, such as reported innovations and innovation activities over a reference period, may lead to biased conclusions, for example when analysing the link between innovation and productivity. A firm may report no innovations in a given period, but this may be the case because it already innovated in the past, and several novel technologies and business practices are already embedded in its operations. This highlights the importance of measuring both flows and stocks.

While statistical frameworks are relatively well developed for capturing evidence of knowledge development, in a world where companies share and sell IP and know-how, and learn from each through imitation, more established innovation statistics do not provide appropriate measures of the utilisation of such knowledge within firms. Measures of technology development and use have to be jointly analysed to address a broad range of policy questions. Many countries have developed strategies to collect information on the use of technologies and business practices across different domains. Examples include the OECD model surveys on ICT usage by businesses and related data collection ${ }^{1}$, statistics on biotechnologies $^{2}$ and nanotechnologies ${ }^{3}$. Ad hoc studies have also been carried out on issues such as the effects of ICT use on innovation (Spiezia, 2011), knowledge management (OECD, 2003a) and design practices (Galindo-Rueda and Millot, 2015). Specific national initiatives collect technology usage data as part of innovation surveys or other types of data collection, such as the US Annual Business Survey, the Swiss Innovation Survey or the Finnish Innovation Survey. However, there has been no concerted effort across countries to attempt to capture information on a comprehensive list of technologies and business practices. Furthermore, this information has rarely been available for analyses jointly with data about innovation.

Statistics Canada collects data on the use of advanced technologies by Canadian firms through the Survey of Advanced Technology (SAT). This survey provides a unique opportunity for modelling the links between a particularly broad range of technology and business practice use on the one hand and innovation behaviour on the other, drawing on actual data. In light of these possibilities, the OECD and Statistics Canada (hereafter STC) developed a partnership to carry out an exploratory analysis aimed at mapping the use of advanced technologies and business practices and assessing their link with innovation, drawing on the SAT data.

\subsection{Key concepts}

Technology is a broad concept that refers to the state of knowledge on how to convert resources into outputs (OECD/Eurostat, 2018). In many cases, the term 'technology' is 
used to refer to "technical" capacity (see left hand side of Figure 1), but in practice it can also refer to capacity to established practices and procedures where a technical component might be indirectly present or not at all (see right side on Business practices). Innovation and technology are connected in multiple ways.

Figure 1. Technology, business practices and innovation

Schematic representation of relationship between different concepts

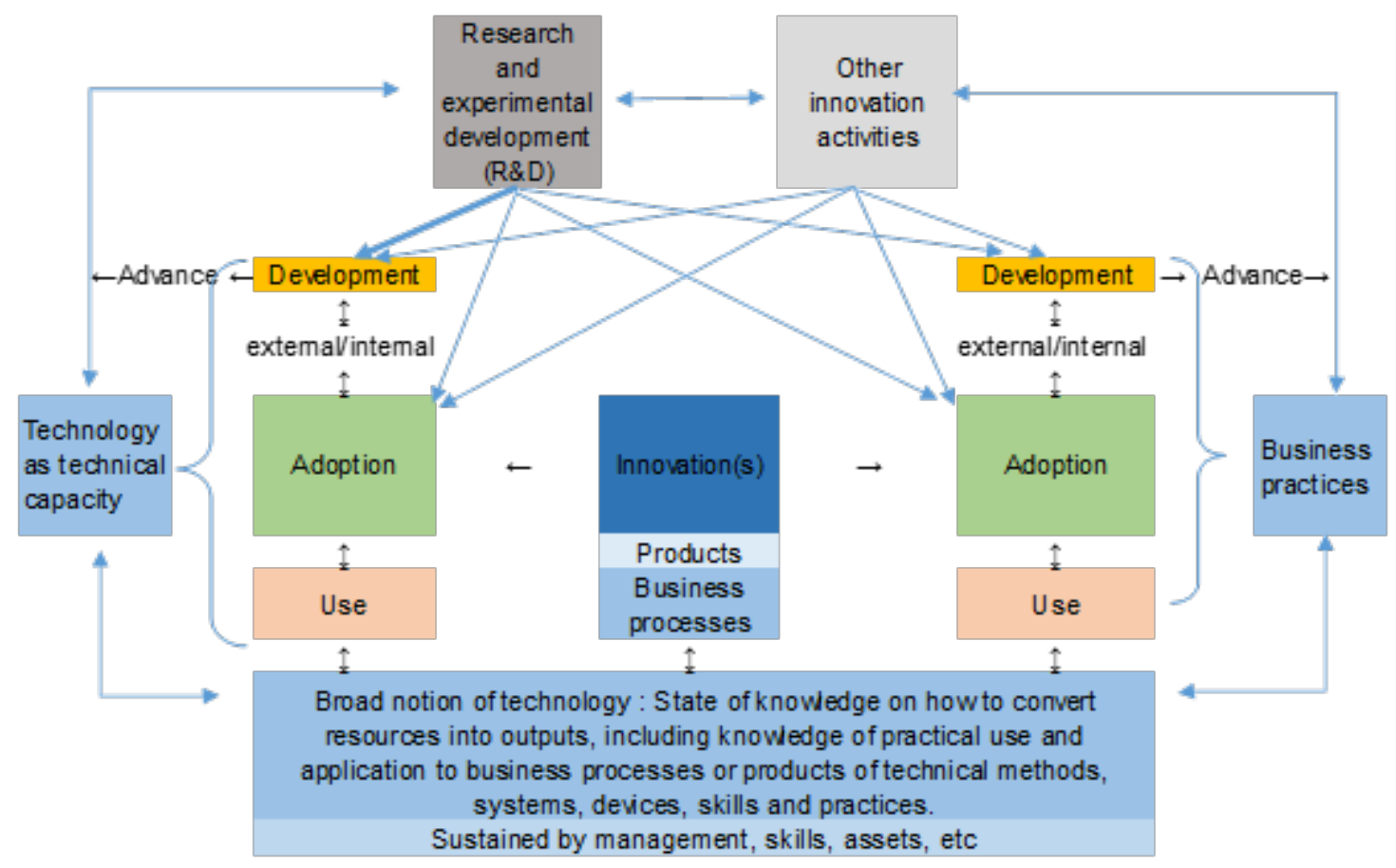

Source: OECD, based on the conceptual framework in the Oslo Manual 2018.

Placed centrally in the figure, Business innovation is defined in the Oslo Manual (OECD/Eurostat, 2018) as "a new or improved product or business process (or combination thereof) that differs significantly from the firm's previous products or business processes and that has been introduced on the market or brought into use by the firm". The manual defines two types of innovation according to whether it represents a change in the firm's products (product innovation) or change in a business process (business process innovation). This is also a broad definition in that it encompasses both products and processes that are completely new to the economy as well as those that are new to the individual firms that implement them. This implies that there exist a class of innovations that represent the diffusion rather than the first time development and implementation of ideas, including technologies. Placed top of the chart and underpinning innovations, innovation activity is the set of activities purposefully carried out with the aim of giving rise to innovations. Research and experimental development $(\mathbf{R} \& \mathbf{D})$, defined as "creative work undertaken in order to increase the stock of knowledge [...] and to devise new applications of available knowledge (OECD, 2015), is a special class of innovation activity ${ }^{4}$ because by definition it aims to enlarge the boundaries of knowledge and technology. In a more general sense, however, other innovation activities could also provide a basis for such advancement, building pre-existing internal as well as "acquired" external capabilities, such as different types of assets, management capabilities or technical expertise. 
However, not all firms are actively involved in the purposeful development of new techniques and business practices. What ultimately matters about technology for a majority of companies is the extent to which it is used and adapted to specific requirements. A firm can adopt and use a particular technology by developing it itself or by acquiring it (e.g. through leasing, licensing or partnership agreements). The process of technology adoption can be considered as innovation as long as it meets the requirement that this is a significant step for the firm to implement it in its processes and products.

The Oslo Manual, since its 2005 edition, does not formally use the term technological innovation in recognition of the fact that technology is often present in all types of innovations (across products and all business processes). Since then, it has recommended instead to characterise and distinguish innovations by their degree of novelty and the extent to which they push knowledge boundaries. What has been effectively missing from the regular measurement of innovation is the comparison of innovation and innovation activity to measures of the level of the overall technological competence of the firm, as for example implied by its use of recently developed techniques and procedures as well as their centrality to the business strategy. The relevance of this distinction for the analysis of productivity and the need to clarify the language around the term "technology" was the main reason for the addition of a new chapter on Business capabilities for innovation in the 2018 edition of the Oslo Manual.

\subsection{Related literature}

Previous research on mapping advanced technologies (ATs) share a number of features with this study. Typologies of ATs based on their functional characteristics or types of application domains (e.g. engineering, manufacturing, business planning) have been proposed in Rosenthal (1984), Meredith (1987), Adler (1988), Lei and Goldhar (1991) and Saraph and Sebastian (1992) $)^{5}$. AT categories defined in these typologies are generally consistent with each other and have served as the basis for subsequent work. In particular, the distribution in three groups of ATs (namely design, manufacturing and administrative technologies) has been widely applied in studies of AT investment patterns in firms. For example, Boyer et al. (1996) have identified four types of enterprises (traditionalists, generalists, high investors and designers) according to their design, manufacturing and administrative AT investment patterns. Similar studies have been carried out on different countries and industries (Diaz et al., 2003, Jonsson, 2000, Chung and Swink, 2009, Bülbül et al., 2013).

The above-mentioned studies focus on the use of advanced technologies in selected manufacturing industries. The scope of the SAT survey and our study is broader and covers non-manufacturing industries, including selected services, and the technologies that serve them (e.g. logistics, geomatics and cloud computing technologies). Including digital technologies in the analysis allow for a better understanding of the digital transformation and its impact on innovation, a topic covered in greater detail in the OECD report entitled Measuring the Digital Transformation: A Roadmap for the Future (OECD, 2019). However, there is still a need to go further to develop a categorisation of ATs that is potentially relevant across all industries.

Studies on the link between AT adoption and firm performance led to somewhat divergent conclusions. Operational performance (e.g. productivity, cost, quality, flexibility, delivery time) and business performance (e.g. sales, profit, market shares) are found to be positively associated with AT adoption in Jonsson (2000), Bülbül et al. (2013) among others, while 
other studies have found no relationship (Diaz et al., 2003, Boyer et al., 1996, Cagliano and Spina, 2000).

Exploring the reasons for the ambiguous impact of ATs on firm performance, Boyer et al. (1996) have raised the possibility of time lags before firms are able to reap the benefits from AT implementations. In Cheng et al. (2018), the use of longitudinal data has shown that the accumulation of a certain level of AT investment is needed before there is an increase in operational performance. The timing of adoption has also been stressed as a key factor by Bourke and Roper (2016), who argue that: early technology adoption influences innovation performance and can enhance the innovation benefits of subsequent technology adoption through a learning-by-doing effect.

Many studies have also identified a number of key variables that appear to contribute to improving firm performance in interaction with ATs. Das and Jayaram (2003) have identified a list of such variables and found that lean manufacturing and work organisation practices are the most complementary to ATs. Indeed, beyond the direct impact of business practices (BPs) on firm performance (see for example Bruhn et al., 2018, Bloom et al., 2011, Bloom et al., 2012, Bloom et al., 2017), BP interactions with ATs have been identified as a key factor in explaining firm performance (see for instance Boyer et. al, 1997, Zhou et al. 2009). A number of empirical studies have in particular focused on the synergetic relationships within Integrated Manufacturing (IM) schemes, a concept defined as the association of advanced manufacturing technologies, total quality management and just-in-time inventory control (see for example Challis, 2002, Khanchanapong et al. 2014).

The link between AT and innovation has been less often explored in the literature. BargeGil et al. (2011) and Santamaría et al. (2009) found that firms using advanced technologies are more likely to innovate. The use of SAT data allows a more in-depth examination of firms' innovation performance according to different patterns of technology usage.

\subsection{Key features of this study}

In this study, information from variables describing BP and AT is combined using different methods in order to assess their integrated use and relationship with innovation performance. Bloom et al. (2016) have shown that management practices, beyond simply reflecting contingent management styles, are similar to technologies in the sense that they monotonically raise firms' economic performance. In their "Management as a technology" model, presented in contrast to a model of management as a fundamentally contextdependent capability ${ }^{6}$, management practices enter in the production function as intangible capital. They find that management practices account for about $30 \%$ of total factor productivity gaps between the countries in their study. Our study also treats each BP variable as a technology, and aims to identify complementarities with other advanced technologies and assess their links with innovation.

In addition to the intrinsic interest in Canada's ATBP use and innovation patterns, and the methodological relevance of this distributed analysis approach, this analysis is of broader potential international interest for two main reasons:

- It informs an initial assessment of how important AT and BP usage patterns can be for explaining innovation and potentially other outcomes. Results can help motivate interest in the data among policymakers in a number of areas, for example in the context of the OECD Going Digital project ${ }^{7}$, or work within the OECD Working Party on Bio, Nano and Converging Technologies and the OECD Working Party on Measurement and Analysis of the Digital Economy. This paper provides an 
initial testing for implementing some of the recommendations arising from the latest edition of the Oslo Manual, in particular "Chapter 5: Measuring business capabilities for innovation". This country-based quantitative analysis can inform whether it is feasible and relevant to collect and use such data.

- It helps test a mechanism for classifying industries according to their patterns of technology use. In the past, the OECD has built technology taxonomies of industries but because of data constraints, $R \& D$ indicators had to be used as proxies for technology content. In this report, we compare alternative industry classification procedures according to technology usage patterns, rather than R\&D intensity. In addition, such exploratory work on sectoral technology content can complement recent OECD work on classifying industries according to their level of digital intensity (Calvino et al., 2018).

The remainder of this paper is structured as follows: Section 2 presents the data on technologies, business practices and innovation used in the analysis, as well as the distributed method of microdata analysis. Section 3 describes the use of a multivariate analysis approach for synthesising information on the several technologies and business practices, identifying general patterns and exploring how they relate to other business characteristics. Section 4 investigates the link between AT and BP usage and innovation. Section 5 summarises the main findings and points at possible future steps. Statistics Canada's Survey of Advanced Technology (SAT)

\section{Working with SAT survey data}

This study is based on Canada's Survey of Advanced Technology (SAT 2014), a survey that took place in 2015. As stated on STC's website, "the objective of the Survey [...] is to collect important information about the extent to which Canadian enterprises use advanced technologies". The survey was conducted with the aim that the information compiled can "be used for market analysis, by trade associations to study performance and other characteristics of their industries, and by government to develop national and regional economic policies and technology strategies". The possible use by STC "for other statistical and research purposes" is also noted.

SAT data allow development of indicators on technology usage, identification of factors influencing technology adoption and diffusion, and assessment of the relationship between technology and innovation. Moreover, linking SAT data with other types of data (such as economic performance data) can potentially broaden their analytical interest.

SAT is not part of the regular set of business surveys carried out by StatCan. Like the Survey on Innovation and Business Strategy, it has been sponsored in the past on an ad hoc basis by the Ministry of Innovation, Science and Economic Development. The latest edition was principally funded by Statistics Canada, with supplementary funding coming from provincial governments to boost their respective samples and thereby allow the publication of more detailed results. Statistics Canada had previously conducted similar surveys on four occasions. Over the previous editions ${ }^{8}$, the target population had progressively 
increased in size and scope: the 1989, 1993 and 1998 surveys covered manufacturing excluding food processing; food as well as logging completed the industry list in the 2007 edition; and the 2014 version includes all manufacturing plus an extended list of nonmanufacturing industries. The SAT surveys covers all manufacturing industries (NAICS 31-33), Forestry and Logging (NAICS 113), Mining, Quarrying, and Oil and Gas Extraction (NAICS 21), Utilities (NAICS 22) and selected service industries, namely Wholesale Trade (NAICS 41), Retail Trade (NAICS 44-45), Transportation and Warehousing (NAICS 48-49), and Professional, Scientific and Technical Services (NAICS 54). All these industries are included in this study and results are presented at the 3-digit level. The SAT survey excludes some non-manufacturing industries, as well as firms with less than 10 employees or less than CAD 250000 in revenues. The exhaustive list of covered industries is presented in Annex 1.

In this study we only use data from the 2014 survey as it represents the most recent and comprehensive survey. Statistics Canada designed the 2014 SAT in collaboration with other federal government agencies. 11887 enterprises were sampled (out of 84322 enterprises in the survey population) following a stratified random sampling by industry, size and region. 7912 firms completed the questionnaire. Error detection and imputation routines where applied where necessary. Individual weights were associated to each firm so that calculated aggregates are representative of the entire population. A dedicated SAT webpage $^{9}$ on the Statistics Canada website provides further information on its methodology.

\subsection{Survey questions used for the analysis in this paper}

\subsubsection{Advanced technology (AT)}

The broad concept of "technology" refers to the state of knowledge on how to convert resources into outputs. This includes the practical use and application to business processes or products of technical methods, systems, devices, skills and practices. However, as commonly used, the term technology is meant to denote something more specific, namely the technical capability to put in motion and control one or more material transformation processes, a concept intimately related to engineering. Capabilities in this area draw on the knowledge and expertise of a firm's workforce, accumulated experience in using technologies and the ability to use assets embedding the 'technology'. The term "Advanced Technology" (AT) is given the following general definition in the survey: "Advanced technology is new technology that performs a new function or improves some function significantly better than other commonly used technology". ${ }^{10}$

Advanced technology is unavoidably a fluid and subjective concept. The STC definition attempts to convey the concept by reference to technologies whose invention or first-time operationalisation as a functioning process is still relatively recent and requires a considerable degree of technical competence to utilise. The SAT survey does not need to go into such detail as it principally operates on a list basis ${ }^{11}$, there being no general question. The SAT design has evolved over time and changed the list of what it considers to be advanced technologies. The 2014 SAT questions on the use of advanced technologies are central to the analysis in this paper. For each proposed technology, respondents are invited to opt for one of the four following options:

- The technology has been used for more than three years in the enterprise.

- The technology has been used for less than three years. 
- The technology has not been used but is planned to be used within the next two years.

- The technology is not used and is not planned to be used.

In the SAT, the technologies explicitly labelled as "advanced" are grouped in four domains or areas: a) Advanced Material Handling, Supply Chain and Logistics Technologies; b) Advanced Business Intelligence Technologies; c) Advanced Design, Information Control, Processing and Fabrication Technologies; and d) Advanced Green Technologies.

Additional technologies included in the survey questionnaire are labelled as "emerging" technologies. These include Geomatics and Geospatial technologies, Nanotechnologies, Biotechnologies, and Bioproducts. The questions asked about these other technologies are only slightly different.

On the basis of the lists provided, the conceptual distinction between advanced and emerging may seem questionable ${ }^{12}$ to many observers. Therefore, for the purpose of the analysis in this paper, the term "advanced technologies" (ATs) hereafter designates the ensemble of all technologies covered in the survey, regardless of the SAT terminology which refers to a smaller subset. The list of the 50 technologies included in the 2014 SAT is available in Annex 2. Annex 3a provides basic descriptive statistics on their individual use based on figures published by STC ${ }^{13}$. Annex 3b shows additional information on the rate of adoption of ATs indicating which ones have experienced greater acceleration (mostly cloud technologies) and which ones were expected to grow fastest (additive manufacturing).

\section{Technology development}

In addition to collecting information on whether a firm uses any given AT, the survey also asks whether the firm is developing technologies. Technology development is normally associated to a higher degree of technical competence, and the use of its results can transcend the firm's own boundaries. For nanotechnologies, biotechnologies and bioproducts, firms are explicitly asked to report on their possible development. Additionally, firms using at least one advanced technology ${ }^{14}$ are asked to specify whether they have integrated them by developing new advanced technologies. Variables on the development of technologies in those domains are derived from those same questions. ${ }^{15}$

\subsubsection{Business practices (BP)}

The concept of business practices (BPs) or methods is also challenging to define and operationalise. Although the SAT does not define them generally, one possible way to think about them is as a sets of activities and procedures used by organisations to fulfil their functions (e.g. deliver a product on time, ensure that it meets certain quality requirements, or maximise customer awareness of it) and meet their ultimate objectives. BPs may involve division of labour within and outside the firm and involve the use of technologies. "BP" is also a particularly broad concept. The SAT survey cannot encompass all BPs and a result a number of choices have been made. Variables on enterprises' business practices or methods presented as question items in SAT include: concurrent engineering, lean manufacturing, six sigma, and collaboration or alliances with universities. For each proposed BP, firms are asked to report whether they regularly use it (yes-no). For this study we decide to separate a generic SAT question on the use of outsourcing for use as a separate control because it does not refer specifically to a business function. Therefore, the term "business practices" (BP) hereafter refers to all practices listed in the SAT survey except 
"outsourcing within Canada" and "outsourcing outside Canada", and encompasses a total of 18 business practices (see Annex 2). Annex 3 provides basic descriptive statistics on their individual use based on figures published by $\mathrm{STC}^{16}$.

\subsubsection{Innovation}

A key aspect of the study is to relate data on technology and business practice adoption to innovation. SAT data contains a set of variables on innovation: firms report whether they are engaged in innovation activities or not, by type of innovation. Three synthetic measures were derived for the analysis:

- introduction of an innovation between 2012 and 2014 (yes/no)

- introduction of a product innovation between 2012 and 2014 (yes/no)

- introduction of a business process ${ }^{17}$ innovation between 2012 and 2014 (yes/no)

Figure 2. Reference periods for AT, BP and innovation data

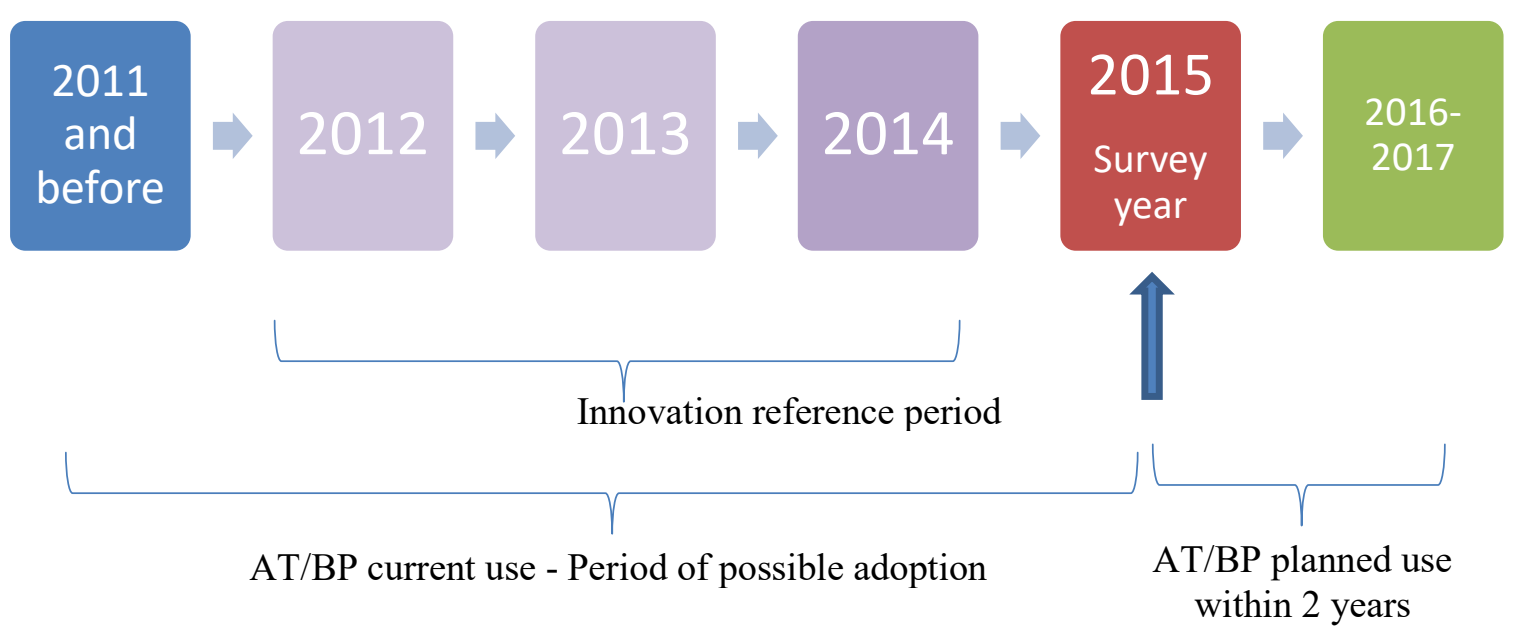

Source: Statistics Canada, Survey of Advanced Technology

It is worth comparing the reference period for innovation and AT/BP questions. This is presented in the schema in Figure 2. In the 2014 edition, innovation questions refer to the 3-year period 2012 to 2014. Questions on the use of ATs, as explained above, are based on a refined time dimension: adopted more than 3 years ago, less than three years ago, anticipated within the next two years, or neither used nor planned. The indicators derived for current use imply adoption times that may range from the point in time in which the survey took place in 2015 up to any point before.

\subsubsection{Other business characteristics}

The analysis integrates other variables of interest ${ }^{18}$ :

- The size of the enterprise: small (10 to 99 employees), medium-sized (between 100 and 249 employees) or large ( 250 and more employees).

- The detailed industry code of the main activity of the enterprise in the North American Industry Classification System (NAICS). 
- The country of control of the enterprise: Canada, the United States, or other.

- Whether the enterprise is outsourcing part of its activity or not (also distinguishing between outsourcing within and outside Canada).

\subsection{Distributed microdata analysis of SAT data}

Tabulations with indicators derived from SAT data are available in the Statistics Canada's tables ${ }^{19}$. The figures are presented in semi-aggregated summary tables by industry, size and region. These indicators are a rich source of descriptive information about Canada although the scope for multivariate analysis is limited. Confidentiality and disclosure control rules prevent additional cross-tabulations with different variables of interest ${ }^{20}$, restraining the potential use of Statistics Canada tables for modelling multi-variable associations.

As the experience of initial innovation surveys shows, conducting analytic work is particularly important for the long term sustainability of initially one-off initiatives such as this study because the descriptive analysis alone is limited by the lack of time series or international benchmarks. Analytic work can help provide the evidence required to prioritise internationally coordinated measurement exercises, or generate sustained support to repeat a survey over time.

For this reason, the OECD proposed to STC to undertake a more in-depth multivariate analysis of the cross sectional SAT data. Because OECD officials are not authorised access to STC microdata in general and SAT data in particular, the analysis was performed on SAT microdata using a distributed approach. This is an arms' length analysis process, so that no confidential data leaves secure STC premises, while allowing for OECD staff to define and codify the analysis in first instance and obtain the non-confidential results so they can be shared more widely. This is a model that can be "distributed" or "federated" across more than one country provided that similar type of data are collected and available. $^{21}$

STC helped OECD understand the formal structure of the data and the SAT microdata file in particular, without revealing its actual contents. The OECD secretariat prepared and sent the SAS ${ }^{\circledR}$ computer code for data processing to STC. STC provided valuable suggestions on the code helping refine it over a couple of iterations. STC ran the code on the SAT microdata. After running a number of confidentiality and disclosure controls, it reported results back to OECD and assisted in their interpretation and preparation of this paper.

\section{Understanding patterns of technology and business practice usage}

\subsection{Making sense of the multidimensional ATBP data}

The SAT database contains a large number of variables (50 on the adoption of advanced technologies and 18 on business practices) that can be used to analyse ATBP use patterns. This represents a considerable degree of complexity that can get in the way of interpretation. To address this, the aim of this section is twofold: 
- to identify groups of "similar" technologies and practices according to patterns of adoption by firms

- to develop firms' profiles depending on their portfolio of technologies and business practices.

\subsubsection{Methods for extracting technology areas as factors}

A data reduction method is necessary to render the data usable for interpretation. The method used to identify associations of ATBPs is factor analysis. It was applied on microlevel data and intended to synthesise the information contained in the large number of variables (68 in total) into a smaller, more manageable number of latent variables called factors. The factor loadings derived from the factor analysis give a measure of the degree of association between the derived factors and the underlying ATBP variables. Each factor can be subsequently interpreted in light of the variables for which loadings are highest or lowest.

The results from the factor analysis enable identification of groups of technologies and business practices simultaneously adopted by firms. Moreover, it is possible to derive measures (called factor scores) reflecting firms' placement on each factor. In our case, the aim of computing factor scores is twofold: discovering which types of firms (by size for example) score high on which factors; and assessing how factor scores relate to innovation performance.

\section{Measuring similarity between technologies for the factor analysis}

The core object of a factor analysis is a covariance (or a correlation) matrix of the input variables. In our case, the raw variables entering into the factor analysis are a set of binary (yes-no) variables indicating whether individual ATBPs had been adopted. We use a matrix of similarity as a covariance matrix into the factor analysis. The measure used to calculate the proximity between technologies is the Jaccard similarity or co-occurrence coefficient: for each pair of technologies, the Jaccard index corresponds to the number of firms using both technologies relative to the number of firms using either one or the other:

$$
J(\text { tech } A, \operatorname{tech} B)=\frac{\#(\text { tech } A \text { is used } \cap \text { tech } B \text { is used })}{\#(\text { tech } A \text { is used } \cup \text { tech } B \text { is used })}
$$

where $\#(X)$ is the number of firms where $X$ occurs. The Jaccard matrix used for the factor analysis consists of the $68 \times 67$ similarity measures connecting all technologies and practices with each other. The matrix is symmetric as $J(\operatorname{tech} A, \operatorname{tech} B)=J(\operatorname{tech} B, \operatorname{tech} A)$ with diagonal elements equal to 1 .

The use of the Jaccard similarity index is motivated by the nature of the data and by the purpose of the analysis. ${ }^{22}$ The Jaccard index has the advantage of ignoring mutual absences, i.e. cases where both ATBPs in a pair are unused. In the context of this analysis, the Jaccard index is preferable as the focus is on mutual adoptions and not mutual absences, an event that is less informative. The impact of choosing one measure or another is not negligible ${ }^{23}$ since use rates are low for a majority of technologies (hence numerous mutual absences).

Annex 4 shows the Jaccard coefficients for the first 30 closest pairs of technologies or business practices in descending order of co-occurrence. Highly related technologies are at the top of the ranking. To cite just the first 3 pairs of technologies that are most frequently used together: "Infrastructure as a service (IaaS) (e.g., cloud computing hardware)" and "Software as a service (AaaS) (e.g., cloud computing software )"; "Mobile device with 
geolocation capabilities" and "Global positioning system (GPS) (exclude personal use)"; and, "Additive manufacturing including rapid prototyping for materials other than plastics and metals, and 3D printing other than plastics and metals" and "Additive manufacturing including rapid prototyping for metals and 3D printing for metals". The first pair of business practices rank 26 ${ }^{\text {th. }}$ "Quality Management System (QMS)" and "Business certification or certification renewals (e.g., ISO 9000, ISO 14000)". The first combination of a technology and a business practice arrives $56^{\text {th }}$ (not shown in Annex 4): "Crossfunctional design teams" and "Virtual Product Development or modelling software including Computer Aided Design (CAD), Computer Aided Engineering (CAE), Computer Aided Manufacturing (CAM)".

\subsubsection{Results: Interpreting the ATBP factors}

The factor analysis based on the Jaccard similarity matrix provides a reduced set of manageable and interpretable data, from which patterns of technology and business practices use can be derived. The results are presented in Table 1. This table shows the factor loadings, which reflect the correlation between the original variables and the factors. The number of retained factors is seven. ${ }^{24}$

Table 1. Factor loadings for advanced technologies and business practices (ATBPs)

\begin{tabular}{|c|c|c|c|c|c|c|c|c|}
\hline $\begin{array}{l}\text { Factor with } \\
\text { highest loading } \\
\text { on ATBP item }\end{array}$ & Technologies and business practices & $\begin{array}{c}\text { Factor } \\
1\end{array}$ & $\begin{array}{c}\text { Factor } \\
2\end{array}$ & $\begin{array}{c}\text { Factor } \\
3\end{array}$ & $\begin{array}{c}\text { Factor } \\
4\end{array}$ & $\begin{array}{c}\text { Factor } \\
5\end{array}$ & $\begin{array}{l}\text { Factor } \\
6\end{array}$ & $\begin{array}{c}\text { Factor } \\
7\end{array}$ \\
\hline 1 & Warehouse Management System (WMS) & $\underline{0.56}$ & 0.15 & 0.04 & 0.00 & 0.02 & -0.03 & 0.01 \\
\hline 1 & Supply chain collaboration and visibility systems & $\overline{0.52}$ & 0.06 & 0.09 & 0.01 & 0.05 & 0.01 & 0.00 \\
\hline 1 & Software for demand forecasting or demand planning & $\underline{0.51}$ & 0.18 & 0.05 & -0.01 & 0.03 & 0.04 & 0.01 \\
\hline 1 & Automated products and parts identification (e.g., bar or QR coding) & $\underline{0.47}$ & 0.15 & 0.02 & -0.01 & 0.04 & 0.06 & 0.01 \\
\hline 1 & Transportation management system & $\underline{0.42}$ & 0.05 & 0.05 & 0.15 & 0.07 & -0.02 & 0.01 \\
\hline 1 & Customer Relationship Management (CRM) software & 0.38 & 0.20 & 0.00 & 0.01 & 0.01 & 0.18 & 0.01 \\
\hline 1 & Automated Storage (AS) and Retrieval System (RS) & $\underline{0.36}$ & 0.03 & 0.06 & 0.02 & 0.12 & 0.04 & 0.01 \\
\hline 1 & Executive dashboards for analytics or decision-making & $\underline{0.35}$ & 0.21 & 0.03 & 0.02 & 0.03 & 0.22 & 0.00 \\
\hline 1 & $\begin{array}{r}\text { Inter-company computer networks including Extranet and electronic } \\
\text { data interchange (EDI) }\end{array}$ & $\underline{0.32}$ & 0.30 & 0.07 & 0.04 & 0.01 & 0.08 & 0.01 \\
\hline 1 & Live stream processing technology or real-time monitoring & $\underline{0.32}$ & 0.13 & 0.07 & 0.08 & 0.04 & 0.27 & -0.01 \\
\hline 1 & Wireless communications for production & $\overline{0.27}$ & 0.25 & 0.15 & 0.10 & 0.06 & 0.10 & 0.00 \\
\hline 1 & Software for large-scale data processing (e.g., Hadoop) & $\underline{0.26}$ & 0.11 & 0.09 & 0.08 & 0.11 & 0.19 & -0.01 \\
\hline 1 & Radio frequency identification (RFID) & $\underline{0.24}$ & -0.01 & 0.07 & 0.10 & 0.05 & 0.01 & 0.01 \\
\hline 1 & $\begin{array}{r}\text { Product Data Management (PDM) or Life Cycle Management } \\
\text { (LCM) }\end{array}$ & $\underline{0.18}$ & 0.18 & 0.13 & 0.06 & 0.06 & 0.03 & 0.00 \\
\hline 2 & $\begin{array}{r}\text { Virtual Product Development or modelling software incl. Computer } \\
\text { Aided Design (CAD), Computer Aided Engineering (CAE), } \\
\text { Computer Aided Manufacturing (CAM) }\end{array}$ & 0.08 & $\underline{0.45}$ & 0.18 & 0.05 & 0.00 & 0.06 & 0.05 \\
\hline 2 & $\begin{array}{r}\text { Continuous improvement (including Total Quality Management } \\
\text { (TQM)) }\end{array}$ & 0.16 & $\underline{0.45}$ & 0.09 & 0.03 & 0.06 & 0.05 & 0.00 \\
\hline 2 & Quality Management System (QMS) & 0.11 & $\underline{0.43}$ & 0.14 & 0.04 & 0.10 & 0.01 & 0.01 \\
\hline 2 & $\begin{array}{r}\text { Business certification or certification renewals (e.g., ISO 9000, ISO } \\
14000)\end{array}$ & 0.11 & $\underline{0.39}$ & 0.13 & 0.01 & 0.10 & 0.01 & 0.02 \\
\hline 2 & Collaboration or strategic alliance with other companies & 0.17 & $\underline{0.38}$ & 0.03 & 0.10 & 0.04 & 0.14 & 0.02 \\
\hline 2 & Cross-functional design teams & 0.09 & $\underline{0.37}$ & 0.15 & 0.06 & 0.06 & 0.05 & 0.04 \\
\hline 2 & Electronic work order management & 0.22 & $\underline{0.35}$ & 0.09 & 0.00 & 0.10 & 0.08 & 0.01 \\
\hline 2 & ADI-Enterprise Resource Planning (ERP) & 0.31 & $\underline{0.33}$ & 0.17 & 0.00 & 0.00 & 0.06 & 0.00 \\
\hline 2 & Lean manufacturing & 0.06 & 0.31 & 0.24 & -0.02 & 0.08 & -0.02 & 0.03 \\
\hline 2 & Just-in-time (JIT) & 0.16 & 0.30 & 0.12 & 0.01 & 0.05 & -0.01 & 0.02 \\
\hline 2 & Concurrent engineering (Simultaneous design) & 0.02 & $\underline{0.30}$ & 0.17 & 0.05 & 0.02 & 0.03 & 0.03 \\
\hline 2 & $\begin{array}{r}\text { Collaboration or strategic alliance with universities, technical } \\
\text { institutes or colleges }\end{array}$ & 0.03 & $\underline{0.24}$ & 0.09 & 0.07 & 0.09 & 0.02 & 0.02 \\
\hline 2 & Competitive Technological Intelligence (CTI) and benchmarking & 0.06 & $\underline{0.22}$ & 0.10 & 0.08 & 0.08 & 0.04 & 0.01 \\
\hline
\end{tabular}




\begin{tabular}{|c|c|c|c|c|c|c|c|c|}
\hline $\begin{array}{l}\text { Factor with } \\
\text { highest loading } \\
\text { on ATBP item }\end{array}$ & Technologies and business practices & $\begin{array}{c}\text { Factor } \\
1\end{array}$ & $\begin{array}{c}\text { Factor } \\
2\end{array}$ & $\begin{array}{c}\text { Factor } \\
3\end{array}$ & $\begin{array}{c}\text { Factor } \\
4\end{array}$ & $\begin{array}{c}\text { Factor } \\
5\end{array}$ & $\begin{array}{l}\text { Factor } \\
6\end{array}$ & $\begin{array}{l}\text { Factor } \\
7\end{array}$ \\
\hline 2 & $\begin{array}{r}\text { Collaboration or strategic alliance with government research } \\
\text { organizations and programs }\end{array}$ & 0.04 & $\underline{0.14}$ & 0.07 & 0.06 & 0.13 & 0.00 & 0.02 \\
\hline 3 & Robot(s) without sensing or vision systems & 0.02 & 0.06 & $\underline{0.41}$ & 0.01 & 0.03 & 0.01 & 0.04 \\
\hline 3 & Manufacturing Resource Planning (MRP II) & 0.16 & 0.20 & $\underline{0.40}$ & -0.02 & 0.02 & 0.00 & 0.03 \\
\hline 3 & Manufacturing Execution System (MES) & 0.09 & 0.07 & $\underline{0.39}$ & 0.01 & 0.02 & 0.00 & 0.09 \\
\hline 3 & Sensor network and integration & 0.13 & 0.06 & 0.39 & 0.15 & 0.06 & 0.06 & 0.01 \\
\hline 3 & Robot(s) with sensing or vision systems & 0.03 & 0.02 & $\overline{0.38}$ & 0.02 & 0.04 & 0.02 & 0.07 \\
\hline 3 & Computer Integrated Manufacturing (CIM) & 0.08 & 0.17 & $\underline{0.37}$ & 0.02 & 0.06 & 0.03 & 0.05 \\
\hline 3 & $\begin{array}{r}\text { Automated systems for inspection (e.g., vision-based, laser-based, } \\
\text { X-ray, high-definition (HD) camera or sensor-based) }\end{array}$ & 0.12 & 0.13 & $\underline{0.36}$ & 0.08 & 0.09 & 0.02 & 0.04 \\
\hline 3 & 4-9 axis computer numerically controlled (CNC) machinery & 0.01 & 0.24 & $\underline{0.35}$ & -0.01 & 0.02 & 0.00 & 0.10 \\
\hline 3 & $\begin{array}{r}\text { Flexible Manufacturing Cells (FMC) or Flexible Manufacturing } \\
\text { Systems (FMS) }\end{array}$ & 0.01 & 0.09 & $\underline{0.31}$ & -0.01 & 0.05 & 0.00 & 0.07 \\
\hline 3 & $\begin{array}{r}\text { Software integration of quality results with planning and control } \\
\text { softwares }\end{array}$ & 0.18 & 0.17 & $\underline{0.29}$ & 0.06 & 0.05 & 0.08 & 0.02 \\
\hline 3 & Virtual manufacturing & 0.03 & 0.10 & $\underline{0.29}$ & 0.03 & 0.00 & 0.04 & 0.13 \\
\hline 3 & Automated machinery for sorting, transporting or assembling parts & 0.05 & 0.04 & $\underline{0.29}$ & 0.02 & 0.08 & 0.01 & 0.07 \\
\hline 3 & Lasers used in materials processing (including surface modification) & 0.00 & 0.11 & 0.29 & 0.00 & 0.05 & 0.02 & 0.13 \\
\hline 3 & Statistical Process Control (SPC) & 0.03 & 0.12 & $\underline{0.28}$ & 0.04 & 0.10 & -0.01 & 0.00 \\
\hline 3 & Six sigma & 0.04 & 0.10 & $\underline{0.22}$ & 0.02 & 0.07 & 0.00 & 0.03 \\
\hline 3 & Quality Function Deployment (QFD) & 0.01 & 0.06 & $\underline{0.16}$ & 0.02 & 0.04 & -0.01 & 0.04 \\
\hline 3 & Distribution Resource Planning (DRP) & 0.10 & 0.12 & $\underline{0.16}$ & 0.06 & 0.08 & -0.02 & 0.03 \\
\hline 3 & Plasma sputtering & 0.00 & 0.03 & $\underline{0.12}$ & 0.02 & -0.01 & -0.01 & 0.09 \\
\hline 4 & Mobile device with geolocation capabilities & 0.11 & 0.09 & -0.01 & 0.57 & 0.04 & 0.03 & 0.01 \\
\hline 4 & Geographic information systems (GIS) & 0.02 & 0.07 & 0.01 & $\underline{0.50}$ & 0.06 & 0.01 & 0.01 \\
\hline 4 & Global positioning system (GPS) (exclude personal use) & 0.14 & 0.13 & -0.03 & $\underline{0.48}$ & 0.05 & 0.02 & 0.01 \\
\hline 4 & Remote sensing (RS) & 0.02 & 0.02 & 0.09 & $\underline{0.45}$ & 0.06 & 0.01 & 0.02 \\
\hline 4 & Spatial data infrastructure & -0.01 & 0.03 & 0.06 & $\underline{0.40}$ & 0.03 & 0.03 & 0.02 \\
\hline 4 & Web or wireless sensors & 0.09 & 0.08 & 0.10 & $\underline{0.38}$ & 0.17 & 0.03 & 0.01 \\
\hline 4 & Unmanned aerial system (e.g., drone) & 0.00 & -0.02 & 0.12 & $\underline{0.13}$ & 0.00 & 0.03 & 0.07 \\
\hline 5 & Waste technologies & 0.09 & 0.11 & 0.06 & 0.02 & $\underline{0.59}$ & 0.04 & 0.01 \\
\hline 5 & Water technologies & 0.04 & 0.07 & 0.08 & 0.05 & $\underline{0.50}$ & 0.00 & 0.01 \\
\hline 5 & Air or emission technologies & 0.10 & 0.09 & 0.09 & 0.06 & 0.42 & 0.04 & 0.01 \\
\hline 5 & Energy technologies (e.g., ISO50000) & 0.06 & 0.06 & 0.08 & 0.07 & $\underline{0.33}$ & 0.00 & 0.02 \\
\hline 5 & $\begin{array}{r}\text { Sustainable development strategy or environmental stewardship } \\
\text { plan (ESP) }\end{array}$ & 0.04 & 0.12 & 0.11 & 0.10 & $\underline{0.12}$ & 0.00 & 0.00 \\
\hline 5 & $\begin{array}{ll}\text { Bioproducts } \\
\end{array}$ & 0.04 & 0.04 & 0.05 & 0.04 & $\underline{0.12}$ & 0.03 & 0.01 \\
\hline 5 & Biotechnologies & 0.00 & 0.04 & 0.05 & 0.04 & $\underline{0.07}$ & 0.00 & 0.01 \\
\hline 6 & Software as a service (AaaS) (e.g., cloud computing software ) & 0.24 & 0.15 & 0.01 & 0.05 & 0.05 & $\underline{0.67}$ & 0.01 \\
\hline 6 & Infrastructure as a service (laaS) (e.g., cloud computing hardware) & 0.19 & 0.12 & 0.05 & 0.08 & 0.05 & $\underline{0.60}$ & 0.02 \\
\hline 7 & $\begin{array}{l}\text { Additive manufacturing including rapid prototyping for metals and } \\
\text { 3D printing for metals }\end{array}$ & 0.01 & 0.00 & 0.08 & 0.00 & 0.01 & 0.00 & $\underline{0.62}$ \\
\hline 7 & $\begin{array}{r}\text { Additive manufacturing including rapid prototyping for materials } \\
\text { other than plastics and metals, and 3D printing other than plastics } \\
\text { and metals }\end{array}$ & 0.02 & -0.01 & 0.06 & 0.00 & 0.00 & 0.01 & $\underline{0.53}$ \\
\hline 7 & $\begin{array}{r}\text { Additive manufacturing including rapid prototyping for plastics and } \\
3 \mathrm{D} \text { printing for plastics }\end{array}$ & 0.01 & 0.07 & 0.18 & 0.04 & 0.00 & 0.01 & $\underline{0.39}$ \\
\hline 7 & Micro-manufacturing (e.g., micro-machining or micro-moulding) & 0.00 & -0.01 & 0.09 & 0.00 & 0.01 & 0.00 & $\underline{0.24}$ \\
\hline 7 & Microelectromechanical Systems (MEMS) & 0.01 & -0.01 & 0.08 & 0.01 & 0.01 & 0.00 & $\underline{0.16}$ \\
\hline 7 & Nanotechnologies & 0.00 & 0.03 & 0.02 & 0.01 & 0.01 & 0.00 & $\underline{0.07}$ \\
\hline
\end{tabular}

Note: Maximum likelihood method and varimax rotation method. For each row, the underlined data point indicates the factor with the highest loading. Factor loadings higher than 0.15 appear in bold. Business practices are shown in italics.

Source: OECD/Statistics Canada analysis of Statistics Canada's Survey of Advanced Technology.

We provide indicative interpretations for each of the seven factors extracted as general ATBP domains: 


\section{Factor 1: Logistics software technologies (LST)}

Factor 1 refers to advanced technologies pertaining to logistics-related software. Variables with significant loadings include technologies to manage and track the flow of products inside or outside the enterprise ("Warehouse Management System (WMS)", "supply chain collaboration and visibility systems"; "automated products and parts identification"; transportation management system; and "Automated Storage (AS) and Retrieval System (RS)"). "Software for demand forecasting or demand planning" as well as "Customer Relationship Management (CRM) software" also correlate positively with this factor. Interrelated technologies enabling the implementation of the above-mentioned tools are also significantly linked to factor 1, e.g. "executive dashboards for analytics or decisionmaking", "Inter-company computer networks including Extranet and electronic data interchange (EDI)", or "live stream processing technology or real-time monitoring".

\section{Factor 2: Management practices and tools (MPT)}

Most business practices load high on this factor. The 4 highest loadings concern "virtual product development or modelling software" technology and quality management practices, namely "continuous improvement (including Total Quality Management (TQM))", "Quality Management System (QMS)" and "business certification or certification renewals (e.g., ISO 9000, ISO 14000)".

\section{Factor 3: Automated production process technologies (APPT)}

Factor 3 displays high loadings for ATs typically used in automated production processes: robots, "Manufacturing Resource Planning (MRP II)", "Manufacturing Execution System (MES)", "sensor network and integration", "Computer Integrated Manufacturing (CIM)", etc. Four business practices have their highest loadings for this factor: "Statistical Process Control (SPC)", "six sigma", "Quality Function Deployment (QFD)" and "Distribution Resource Planning (DRP)".

\section{Factor 4: Geomatics and geospatial technologies (GGT)}

Factor 4 is highly connected with all geomatics and geospatial technologies: "mobile device with geolocation capabilities", "geographic information systems (GIS)", "global positioning system (GPS)", "Remote sensing (RS)", "spatial data infrastructure" and "web or wireless sensors". In addition, "unmanned aerial system (e.g., drone)" is weakly correlated to all factors but has its highest loading on this factor.

\section{Factor 5: Bio-and-environmental technologies (BBT)}

Factor 5 highlights a pattern of technology usage based on green technologies (waste, water, air and energy technologies). The business practice "sustainable development strategy or environmental stewardship plan (ESP)" as well as the biotechnologies and bioproducts are also associated to this factor, albeit slightly.

\section{Factor 6: Software and infrastructure as a service (SIAS)}

Factor 6 is most closely related to "Software as a service (AaaS) (e.g., cloud computing software)" and "Infrastructure as a service (IaaS) (e.g., cloud computing hardware)". Correlations with other variables are negligible, except with "Executive dashboards for analytics or decision-making", "Live stream processing technology or real-time 
monitoring", "Software for large-scale data processing (e.g., Hadoop)" and CRM software solutions.

\section{Factor 7: Additive and micro manufacturing technologies (AMT)}

Additive manufacturing, including rapid prototyping and 3D printing (and to a lesser extent micro-manufacturing) are associated to factor 7 . This is the only factor that nanotechnology use correlates with, with a rather weak signal as the incidence of nanotechnology use across firms is low, as shown in Annex 3.

The seven factors are indicative of thematic technology and business practice areas used by firms. However, it may be that this list does not include the full array of possibilities open to firms. To the extent that our analysis cannot capture other technologies and practices excluded from the survey, our results may reflect correlations with omitted ATBPs.

\subsection{Accounting for differences in factors}

From the factor analysis, it is possible to obtain scores for each factor and each firm. A high factor score indicates a significant use of technologies or practices positively linked to this factor. For instance, firms with high score on factor 1 are intensively using logistics software technologies such as warehouse management systems or CRM software. Our next question is to explore to what extent the degree of use of a certain ATBP factor can be explained by differences in business characteristics

\subsubsection{Differences by size and control}

Table 2 investigates to what extent the adoption of certain ATBP groups is associated to specific characteristics of the firm, namely its size, its country of control, and whether or not part of its activity is outsourced ${ }^{25}$.

\section{Size patterns}

Studies on mapping advanced technologies are in many cases refined by cross-tabulating categories of technology usage with firm size. A correlation is likely to arise as the probability that any business activity (e.g. innovation) is identified increases with the number of individuals that might engage in or arrive at it. Furthermore, given the resources and synergies that AT implementation appears to require, size is generally considered conducive to adoption potentially even after normalising for the previous baseline effect. One key question is whether firm size affects technology adoption in the same way for all types of technologies. Swamidass and Kotha (1998) found differentiated effects depending on the technology considered. Large firms are more likely to adopt technologies with high initial investment costs (e.g. flexible manufacturing systems), as shown in Swamidass and Kotha (1998) and Mansfield (1993). There is no consensus on the impact of firm size on the adoption of cloud computing, a technology with minimal initial costs (e.g. with payment mechanisms such as "pay-as-you-go") and scale flexibility. Despite its attractiveness for small and medium-sized enterprises (see Sultan, 2011, Avram, 2014), some studies find a positive relationship between size and cloud implementation (see for example Low et al, 2011, Oliveira et al, 2014). Hsu et al. (2014) find no significant relationship but they show that factors influencing cloud adoption vary by firms' size class: perceived benefits and IT capabilities are significant factors influencing cloud adoption intention in large firms, while they are not within small firms. 
Table 2. Technology usage, practice usage and business characteristics

OLS regressions of factor scores on firm characteristics

\begin{tabular}{|c|c|c|c|c|c|c|c|}
\hline & $\begin{array}{l}\text { Factor 1: } \\
\text { Logistics } \\
\text { software } \\
\text { technologies } \\
\text { (LST) }\end{array}$ & $\begin{array}{l}\text { Factor 2: } \\
\text { Management } \\
\text { practices and } \\
\text { tools } \\
\text { (MPT) }\end{array}$ & $\begin{array}{l}\text { Factor 3: } \\
\text { Automated } \\
\text { production } \\
\text { process } \\
\text { technologies } \\
\text { (APPTs) }\end{array}$ & $\begin{array}{l}\text { Factor 4: } \\
\text { Geomatics } \\
\text { and } \\
\text { geospatial } \\
\text { technologies } \\
\text { (GGT) }\end{array}$ & $\begin{array}{l}\text { Factor 5: Bio- } \\
\text { and- } \\
\text { environmental } \\
\text { technologies } \\
\text { (BBT) }\end{array}$ & $\begin{array}{c}\text { Factor 6: } \\
\text { Software and } \\
\text { infrastructure } \\
\text { as a service } \\
\text { (SIAS) }\end{array}$ & $\begin{array}{c}\text { Factor } 7: \\
\text { Additive and } \\
\text { micro } \\
\text { manufacturing } \\
\text { technologies } \\
\text { (AMMT }\end{array}$ \\
\hline Intercept & $\begin{array}{c}-0.084^{* * *} \\
(0.011)\end{array}$ & $\begin{array}{l}-0.007 \\
(0.01)\end{array}$ & $\begin{array}{l}0.021^{* *} \\
(0.008)\end{array}$ & $\begin{array}{c}-0.044^{* * *} \\
(0.008)\end{array}$ & $\begin{array}{l}0.041^{* * *} \\
(0.008)\end{array}$ & $\begin{array}{c}-0.059^{* * *} \\
(0.011)\end{array}$ & $\begin{array}{c}-0.017^{\star * *} \\
(0.004)\end{array}$ \\
\hline \multicolumn{8}{|l|}{$\begin{array}{l}\text { Small firms } \\
\text { (set to 0) }\end{array}$} \\
\hline $\begin{array}{l}\text { Medium- } \\
\text { sized firms }\end{array}$ & $\begin{array}{c}0.181^{* * *} \\
(0.01)\end{array}$ & $\begin{array}{c}0.152^{\star * \star} \\
(0.01)\end{array}$ & $\begin{array}{l}0.061^{* * *} \\
(0.007)\end{array}$ & $\begin{array}{c}0.002 \\
(0.008)\end{array}$ & $\begin{array}{c}0.005 \\
(0.007)\end{array}$ & $\begin{array}{l}0.007 \\
(0.01)\end{array}$ & $\begin{array}{l}-0.01^{* *} \\
(0.003)\end{array}$ \\
\hline Large firms & $\begin{array}{l}0.34^{* * *} \\
(0.012)\end{array}$ & $\begin{array}{l}0.214^{* * *} \\
(0.012)\end{array}$ & $\begin{array}{l}0.132^{* * *} \\
(0.008)\end{array}$ & $\begin{array}{c}0.076^{* * *} \\
(0.009)\end{array}$ & $\begin{array}{l}0.058^{* * *} \\
(0.009)\end{array}$ & $\begin{array}{l}0.025^{\star} \\
(0.012)\end{array}$ & $\begin{array}{l}-0.009^{*} \\
(0.004)\end{array}$ \\
\hline \multicolumn{8}{|l|}{$\begin{array}{l}\text { Canadian- } \\
\text { controlled } \\
\text { (set to 0) }\end{array}$} \\
\hline $\begin{array}{l}\text { US- } \\
\text { controlled }\end{array}$ & $\begin{array}{l}0.167^{\star * *} \\
(0.016)\end{array}$ & $\begin{array}{l}0.097^{* * *} \\
(0.015)\end{array}$ & $\begin{array}{l}0.08^{* * *} \\
(0.011)\end{array}$ & $\begin{array}{c}-0.057^{* * *} \\
(0.012)\end{array}$ & $\begin{array}{l}0.046^{* * *} \\
(0.011)\end{array}$ & $\begin{array}{l}-0.015 \\
(0.015)\end{array}$ & $\begin{array}{l}-0.003 \\
(0.005)\end{array}$ \\
\hline $\begin{array}{l}\text { Controlled } \\
\text { by another } \\
\text { country }\end{array}$ & $\begin{array}{c}0.137^{* * *} \\
(0.017)\end{array}$ & $\begin{array}{l}0.136^{* * *} \\
(0.016)\end{array}$ & $\begin{array}{c}0.074^{* * *} \\
(0.011)\end{array}$ & $\begin{array}{c}-0.053^{* * *} \\
(0.012)\end{array}$ & $\begin{array}{l}0.044^{* * *} \\
(0.012)\end{array}$ & $\begin{array}{l}-0.047^{* *} \\
(0.016)\end{array}$ & $\begin{array}{l}-0.014^{*} \\
(0.006)\end{array}$ \\
\hline $\begin{array}{l}\text { Outsourcing } \\
\text { within } \\
\text { Canada }\end{array}$ & $\begin{array}{c}0.051^{* * *} \\
(0.01)\end{array}$ & $\begin{array}{l}0.158^{* * *} \\
(0.009)\end{array}$ & $\begin{array}{c}0.012 \\
(0.007)\end{array}$ & $\begin{array}{c}0.039^{* * *} \\
(0.007)\end{array}$ & $\begin{array}{l}0.029^{* * *} \\
(0.007)\end{array}$ & $\begin{array}{c}0.036^{\star * *} \\
(0.01)\end{array}$ & $\begin{array}{l}-0.001 \\
(0.003)\end{array}$ \\
\hline $\begin{array}{l}\text { Outsourcing } \\
\text { outside } \\
\text { Canada }\end{array}$ & $\begin{array}{l}0.073^{* * *} \\
(0.012)\end{array}$ & $\begin{array}{l}0.156^{* * *} \\
(0.012)\end{array}$ & $\begin{array}{l}0.045^{* * *} \\
(0.008)\end{array}$ & $\begin{array}{l}-0.002 \\
(0.009)\end{array}$ & $\begin{array}{l}0.033^{* * *} \\
(0.009)\end{array}$ & $\begin{array}{l}0.05^{\star * *} \\
(0.012)\end{array}$ & $\begin{array}{l}0.018^{* * *} \\
(0.004)\end{array}$ \\
\hline $\begin{array}{l}\text { Industry } \\
\text { dummies }\end{array}$ & Yes & Yes & Yes & Yes & Yes & Yes & Yes \\
\hline $\mathrm{N}$ & 7912 & 7912 & 7912 & 7912 & 7912 & 7912 & 7912 \\
\hline $\mathrm{R} 2$ & 0.24 & 0.38 & 0.21 & 0.19 & 0.07 & 0.08 & 0.04 \\
\hline
\end{tabular}

Note: $* * *$ : p-value $<=0.001 ; * *: 0.001<$ p-value $<=0.01 ; *: 0.01<$ p-value $<=0.05$.

Source: OECD/Statistics Canada analysis of Statistics Canada's Survey of Advanced Technology.

In our sample, the adoption of advanced technologies and practices is positively correlated to the size of firms when taking into account other factors such as industry specificities which are included in the regressions. This link is distinctly observed for technologies and practices behind factors one, two and three (logistics software technologies, management practices and tools, automated production process technologies). Large firms use more geomatics/geospatial and bio-and-environmental technologies, whereas being a small or medium-sized firm has no impact. The relationship between size and "software and infrastructure as a service" (factor 6) is small, which is consistent with the views that cloud technologies contribute to the scaling up of firms as they allow them to run processes that would have been prohibitively costly to own for small sized businesses. Smaller firms appear in turn to be more likely to use "additive and micro manufacturing technologies" (AMMT) after controlling for other characteristics.

The general large size advantage is confirmed by more detailed analysis of ATBP use patterns and the level of individual technologies and BPs by size, presented in Annex 5. This analysis does not account for systematic differences across industries (i.e. it presents unconditional differences). When viewed from this perspective, it is possible to note that 
there is a size advantage for AMMT use, but as the results in Table 2 show this is entirely driven by the fact that AMMT-using firms (these are a small group) are in sectors where firms are generally larger than the average, but those firms are among the smallest within those sectors. This example indicates the importance of multivariate analysis for analysing industry and size effects.

The ATBPs with the largest unconditional size gap are related to factor 3 (production process technologies). In particular, robots without sensing or vision systems, Manufacturing Execution System (MES), and sensor network and integration are 8 to 11 times more likely to be implemented by large firms than small ones.

Unconditional estimates of size differentials confirm the finding that software and infrastructure as a service (including cloud computing) technologies are relatively well diffused in small firms, underlining the ease of adoption and the limited maintenance costs of such technologies.

\section{Country of control effect}

Foreign-controlled firms implement more logistics software technologies, management practices and tools, production process technologies and bio-and-environmental technologies than Canadian-controlled firms. No significant difference is noticeable between firms controlled by the United States and other countries. However, Canadiancontrolled companies are more likely to be users of geomatics and geospatial technologies. Finally, the relation between the controlling country and factors 6 (SIAS) and 7 (AMMT) is less obvious. There is, however, a higher propensity to adopt software and infrastructure as a service technologies in nationally and US controlled firms than in other foreigncontrolled firms, indicating a sort of "North American" ownership effect. This raises a question as to whether management capabilities or expertise differences by country are potential factors driving differences in technology adoption.

\section{Outsourcing}

Overall, firms with outsourced activities are more likely to use ATPBs, all other things being equal. If this represents a causal relationship, this can operate in either direction but the SAT data only allows to examine some general patterns. For some technologies, this relationship depends on whether activities are outsourced within or outside Canada: in particular, outsourcing outside Canada is associated with the use of APPTs, whereas outsourcing inside Canada is not. This may relate the different labour and pay requirements associated to automated production processes. In contrast, the use of geomatics and geospatial technologies is positively linked to outsourced activities inside - but not outside - Canada. In addition, outsourcing is strongly linked to management practices and tools (factor 2- MPT).

\subsection{Industry patterns of ATBP use}

From the microdata-based analysis previously described, industry profiles can be defined according to their portfolio of technologies and business practices. This approach is in continuation of past OECD studies on technology classifications. In previous OECD work (Hatzichronoglou, 1997; OECD, 2003b), Research and Development (R\&D) expenditure was used as a proxy for assessing the technology content of manufacturing industries ${ }^{26}$. In Galindo-Rueda and Verger (2016), the taxonomy is also based on R\&D and is extended to all industries including services. 
Although this exploratory work applies to a single country, one period and an incomplete industry list, a key interest in using SAT data is the availability of direct measures of technology usage. In the above-mentioned OECD work, R\&D is the only criterion for partitioning industries, whereas technology can derive from channels other than R\&D expenditure. In addition, this part of the analysis also complements recent OECD work (Calvino et al., 2018) on defining a taxonomy of digital intensive sectors based on several criteria covering purchases of ICT intermediates and capital goods, robot use, ICT specialists and online sales.

\subsubsection{Unconditional differences in ATBP use across industries}

Figure 3 examines average ATBP use factors by industries as a first step to identify sectoral patterns to ATBP adoption. The results in part (2a) list the industries highlighting in different colour shades which ATBPS display a relatively high or low rate of adoption within that industry. To facilitate the identification of similar industries, we conduct a hierarchical cluster analysis based on Ward's method. This allows us to classify industries into five broad groups according to their ATBP profiles (Figure 3, part 2b). This provides an interesting contrast with the ISIC (and its Canadian NAICS implementation) classification which focuses on the products rather than on processes for the classification of economic activities. 
Figure 3. ATBP factor scores by industry

Figure 3a. Industries listed by NAICSs code

\begin{tabular}{|c|c|c|c|c|c|c|c|}
\hline & $\begin{array}{l}\text { Factor 1: } \\
\text { Logistics } \\
\text { software } \\
\text { technologies }\end{array}$ & $\begin{array}{l}\text { Factor 2: } \\
\text { Management } \\
\text { practices and } \\
\text { tools }\end{array}$ & $\begin{array}{c}\text { Factor 3: } \\
\text { Automated } \\
\text { production } \\
\text { process } \\
\text { technologies }\end{array}$ & $\begin{array}{c}\text { Factor } 4: \\
\text { Geomatics and } \\
\text { geospatial } \\
\text { technologies }\end{array}$ & $\begin{array}{l}\text { Factor 5: Bio- } \\
\text { and- } \\
\text { environmental } \\
\text { technologies }\end{array}$ & $\begin{array}{c}\text { Factor 6: } \\
\text { Software and } \\
\text { infrastructure as } \\
\text { a service }\end{array}$ & $\begin{array}{c}\text { Factor } 7: \\
\text { Additive and } \\
\text { micro } \\
\text { manufacturing } \\
\text { technologies }\end{array}$ \\
\hline 113-Forestry and logging & -0.16 & -0.05 & -0.05 & 0.21 & 0.02 & -0.08 & -0.01 \\
\hline 211-Oil and gas extraction & -0.09 & 0.00 & -0.02 & 0.24 & 0.13 & 0.17 & 0.00 \\
\hline 212-Mining and quarrying (except oil and gas) & 0.02 & 0.07 & 0.04 & 0.20 & 0.12 & 0.00 & -0.01 \\
\hline 213-Support activities for mining, and oil and gas extraction & -0.05 & 0.02 & -0.01 & 0.13 & 0.02 & 0.00 & -0.01 \\
\hline 221-Utilities & 0.05 & 0.13 & -0.03 & 0.35 & 0.07 & 0.09 & -0.01 \\
\hline 311-Food manufacturing & -0.01 & 0.06 & 0.05 & -0.04 & 0.05 & -0.05 & -0.02 \\
\hline 312-Beverage and tobacco product & -0.01 & 0.01 & 0.00 & -0.01 & 0.10 & -0.09 & -0.01 \\
\hline 313-Textile mills & 0.01 & 0.13 & 0.03 & -0.07 & 0.01 & -0.08 & -0.01 \\
\hline 314-Textile product mills & -0.07 & 0.07 & 0.02 & -0.04 & -0.02 & -0.06 & 0.00 \\
\hline 315-Clothing & -0.02 & 0.02 & 0.03 & -0.06 & -0.03 & -0.10 & -0.01 \\
\hline 316-Leather and allied product & -0.04 & 0.03 & 0.05 & -0.05 & -0.03 & -0.06 & -0.01 \\
\hline 321-Wood product & -0.04 & 0.10 & 0.12 & 0.01 & 0.01 & -0.07 & -0.01 \\
\hline 322-Paper product & 0.10 & 0.19 & 0.12 & 0.00 & 0.09 & -0.04 & -0.01 \\
\hline 323-Printing and related support activities & -0.02 & 0.04 & 0.03 & -0.06 & 0.03 & 0.00 & 0.00 \\
\hline 324-Petroleum and coal product & 0.05 & 0.21 & 0.06 & 0.03 & 0.16 & -0.07 & -0.01 \\
\hline 325-Chemical manufacturing & 0.10 & 0.26 & 0.09 & -0.02 & 0.11 & -0.04 & -0.03 \\
\hline 326-Plastics and rubber products & 0.03 & 0.27 & 0.15 & -0.05 & 0.01 & -0.08 & 0.00 \\
\hline 327-Non-metallic mineral product & -0.04 & 0.07 & 0.07 & 0.01 & 0.08 & -0.03 & 0.00 \\
\hline 331-Primary metal & 0.02 & 0.33 & 0.15 & -0.05 & 0.02 & -0.07 & 0.00 \\
\hline 332-Fabricated metal product & -0.04 & 0.28 & 0.17 & -0.06 & 0.03 & -0.08 & 0.04 \\
\hline 333-Machinery & -0.03 & 0.37 & 0.16 & -0.07 & -0.02 & -0.07 & 0.03 \\
\hline 334-Computer and electronic product & 0.08 & 0.42 & 0.15 & -0.05 & -0.03 & 0.00 & 0.04 \\
\hline 335-Electrical equipment, appliance and component & 0.04 & 0.42 & 0.12 & -0.09 & -0.02 & -0.12 & 0.02 \\
\hline 336-Transportation equipment & 0.02 & 0.40 & 0.19 & -0.08 & 0.01 & -0.11 & 0.01 \\
\hline $337-$ Furniture and related product & -0.04 & 0.17 & 0.14 & -0.07 & 0.00 & -0.06 & 0.02 \\
\hline 339-Miscellaneous manufacturing & 0.02 & 0.22 & 0.14 & -0.06 & -0.02 & -0.05 & 0.04 \\
\hline 411-Farm product merchant wholesalers & 0.00 & -0.06 & 0.00 & -0.01 & 0.00 & 0.03 & -0.01 \\
\hline 412-Petroleum (and products) merchant wholesalers & 0.07 & -0.07 & -0.04 & 0.10 & 0.00 & -0.05 & -0.01 \\
\hline 413-Food, beverage and tobacco merchant wholesalers & 0.08 & -0.02 & -0.02 & 0.00 & 0.01 & -0.07 & -0.01 \\
\hline 414-Personal and household goods merchant wholesalers & 0.25 & 0.02 & -0.03 & -0.08 & -0.04 & 0.01 & 0.00 \\
\hline 415-Motor vehicle merchant wholesalers & 0.16 & -0.05 & -0.03 & -0.03 & -0.04 & 0.00 & 0.00 \\
\hline 416-Building material and supplies merchant wholesalers & 0.06 & 0.01 & 0.01 & -0.03 & -0.01 & -0.03 & 0.01 \\
\hline 417-Machinery, equip. and supplies merchant wholesalers & 0.12 & 0.05 & 0.00 & -0.01 & -0.04 & 0.04 & 0.01 \\
\hline 418-Miscellaneous merchant wholesalers & 0.11 & 0.04 & -0.02 & 0.04 & 0.02 & -0.02 & -0.01 \\
\hline 419-B-to-B electronic markets, and agents and brokers & 0.00 & -0.05 & -0.02 & 0.02 & -0.03 & 0.03 & -0.01 \\
\hline 441-Motor vehicle and parts dealers & 0.05 & -0.06 & -0.07 & -0.06 & 0.05 & 0.14 & -0.01 \\
\hline 442-Furniture and home furnishings stores & 0.27 & -0.09 & -0.12 & 0.07 & 0.15 & -0.09 & 0.00 \\
\hline 443-Electronics and appliance stores & 0.17 & -0.12 & -0.09 & 0.01 & 0.05 & 0.10 & 0.00 \\
\hline 444-Building material and garden equip. and supplies dealers & 0.11 & 0.05 & -0.08 & 0.01 & -0.01 & 0.04 & -0.01 \\
\hline 445-Food and beverage stores & 0.02 & -0.11 & -0.02 & -0.06 & 0.02 & -0.09 & -0.01 \\
\hline 446-Health and personal care stores & 0.09 & -0.15 & -0.02 & -0.06 & -0.02 & -0.06 & -0.01 \\
\hline 447-Gasoline stations & -0.07 & -0.17 & -0.02 & -0.04 & 0.03 & -0.10 & 0.00 \\
\hline 448-Clothing and clothing accessories stores & 0.24 & -0.03 & -0.05 & -0.09 & -0.06 & 0.13 & -0.01 \\
\hline 451-Sporting goods, hobby, book and music stores & -0.01 & -0.16 & -0.03 & -0.03 & -0.04 & 0.09 & 0.01 \\
\hline 452-General merchandise stores & 0.24 & -0.15 & -0.05 & -0.04 & 0.01 & -0.07 & -0.01 \\
\hline 453-Miscellaneous store retailers & 0.07 & -0.12 & -0.03 & -0.02 & -0.04 & -0.08 & -0.01 \\
\hline 454-Non-store retailers & 0.26 & -0.06 & -0.09 & 0.11 & -0.08 & 0.02 & 0.00 \\
\hline 481-Air transportation & 0.10 & -0.01 & -0.05 & 0.21 & 0.02 & 0.00 & 0.00 \\
\hline 482-Rail transportation & 0.09 & -0.07 & 0.00 & 0.19 & -0.01 & -0.05 & -0.02 \\
\hline 483-Water transportation & -0.04 & -0.01 & -0.07 & 0.20 & 0.09 & 0.03 & -0.01 \\
\hline 484-Truck transportation & 0.08 & -0.09 & -0.06 & 0.22 & 0.02 & -0.03 & -0.01 \\
\hline 485-Transit and ground passenger transportation & 0.00 & -0.14 & -0.05 & 0.14 & 0.01 & -0.01 & 0.00 \\
\hline 486-Pipeline transportation & 0.12 & 0.15 & -0.01 & 0.41 & 0.06 & 0.09 & -0.02 \\
\hline 487-Scenic and sightseeing transportation & -0.13 & -0.12 & -0.04 & 0.08 & -0.01 & 0.03 & 0.00 \\
\hline 488-Support activities for transportation & 0.10 & -0.03 & -0.02 & 0.15 & 0.03 & -0.04 & -0.01 \\
\hline 491-Postal service & -0.02 & -0.15 & -0.01 & 0.06 & -0.03 & -0.04 & 0.00 \\
\hline 492-Couriers and messengers & 0.04 & -0.05 & -0.03 & 0.19 & 0.00 & 0.04 & -0.01 \\
\hline 493-Warehousing and storage & 0.21 & -0.01 & -0.04 & 0.01 & -0.03 & -0.03 & -0.01 \\
\hline 541-Professional, scientific and technical services & -0.08 & 0.06 & -0.02 & 0.05 & -0.02 & 0.15 & 0.00 \\
\hline
\end{tabular}

Note: Factor scores for each firm were computed and averaged by industry.

Source: OECD/Statistics Canada analysis of Statistics Canada's Survey of Advanced Technology. 
26 PATTERNS OF INNOVATION, ADVANCED TECHNOLOGY USE AND BUSINESS PRACTICES IN CANADIAN FIRMS

Figure $3 b$. Industries listed by cluster groupings

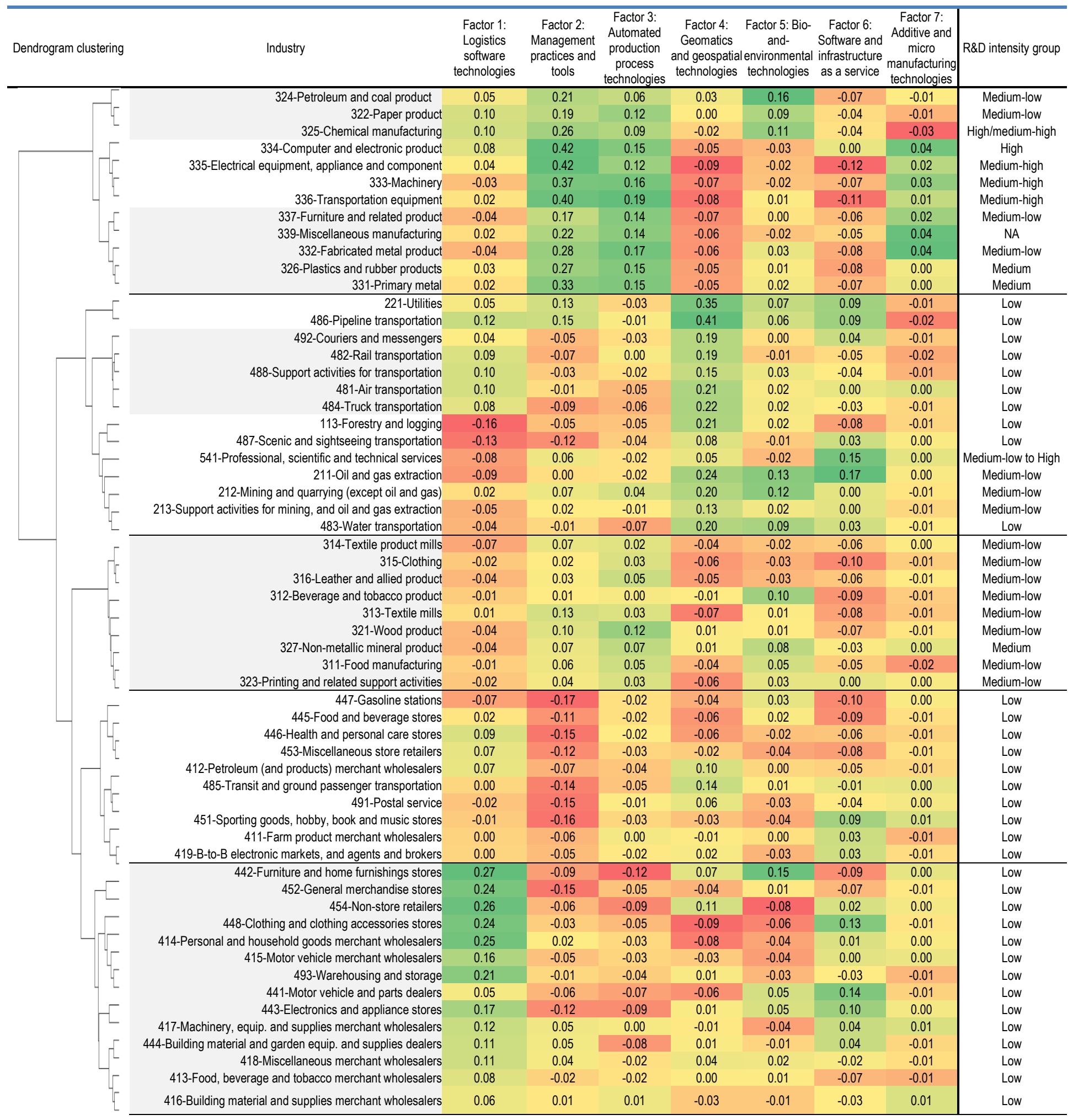

Note: Factor scores for each firm were computed and averaged by industry.

Source: OECD/Statistics Canada analysis of Statistics Canada's Survey of Advanced Technology. 
The results show distinct patterns for manufacturing and non-manufacturing industries. Within manufacturing, a group of ATBP-intensive industries arises from the cluster analysis. It includes, amongst others, the petroleum and coal product, the chemical product, the computer and electronic product, the electrical equipment, the transportation and metal product industries. These industries have in common an intense use of automated production process technologies (APPT) and "management practices and tools" (MPT). Their relatively low scores on the other factors indicate relatively less usage of logistics software technologies (LST), geomatics and geospatial technologies (GGT), software and infrastructure as a service (SIAS). Differences within this group help identify different types of ATBP-intensive industries. For example, the petroleum products, paper products and chemical industry are characterised by higher levels of use of bio-and-environmental technologies (BBT).

Other manufacturing industries are classified in a less ATBP-intensive group (third broad group from the top) and includes the textile, clothing, leather, beverage and tobacco, wood, food, printing and non-metallic mineral product industries.

Outside manufacturing, coverage of the business sector is as noted earlier not complete but extends on this survey to several service sectors. One group encompasses a large part of the wholesale and retail industry and is mainly characterised by an intensive use of logistics software technologies, a moderate usage of software and infrastructure as a service, and a low use of the other ATBP areas.

The second non-manufacturing group highlighted here comprises industries making intensive use of geomatics and geospatial technologies. It includes resource-based industries, transportation services as well as professional, scientific and technical services. This group also exhibits some industries with moderate-to-high usage of bio-andenvironmental technologies and/or software and infrastructure as a service. The remaining service industries are classified in a low ATBP-intensive group. In light of Canada's economic structure and the importance of natural resources, it looks as if the professional services industry shares a number of ATBP patterns with the companies they predominantly support. We speculate that if this exercise were to be repeated in an economy with different economic structure, the professional services industry would be clustered with a different group of industries.

The comparison of industries' technology composition with industry groupings based on R\&D intensity (defined in the last OECD taxonomy of industry in Galindo-Rueda and Verger, 2016) shows a rather good correlation between R\&D effort and technology usage in the manufacturing industry. In the non-manufacturing industries, $R \& D$ and technology use are seemingly uncorrelated. Most service sectors are classified as low R\&D intensive whereas many of display a high degree of technology use, highlighting the limitations of $\mathrm{R} \& \mathrm{D}$ measures as proxies for advance technology content in non-manufacturing industries. ${ }^{27}$

\subsubsection{Conditional differences in ATBP use by industry}

Because sectoral patterns may also reflect other business characteristics, Annex 6 provides for completeness the results for the industry patterns based on the regression coefficients for the industry dummies in the specification presented in 3.2. The results are largely consistent. 


\section{Technology usage, business practices and innovation}

\subsection{The link with innovation}

The previous section has shed some light on combinations of technology and business practices adopted by different categories of firms. This section follows by analysing to what extent these patterns are associated to innovation activities. Using technologies and business practices is highly correlated with innovation. As shown in Table 3, among firms using at least one advanced technologies (63\% of the sample, using the definition used by STC), two thirds are found to be innovative (i.e. to have introduced an innovation during the reference period 2012-2014). In contrast, only one third of firms who report not using AT are innovative.

Table 3. Innovation and advanced technology (AT) use

\begin{tabular}{rcc|c}
\hline & $\begin{array}{c}\text { Using advanced } \\
\text { technologies (as } \\
\text { defined by STC) }\end{array}$ & $\begin{array}{c}\text { Not using advanced } \\
\text { technologies }\end{array}$ & Total \\
\hline Innovative firms & $43 \%$ & $12 \%$ & $55 \%$ \\
Non-innovative firms & $21 \%$ & $25 \%$ & $45 \%$ \\
\hline Total & $63 \%$ & $37 \%$ & $100 \%$ \\
\hline
\end{tabular}

Source: OECD/Statistics Canada analysis of Statistics Canada's Survey of Advanced Technology

The association between business practices (BP) use and innovation is even more pronounced than for ATs. As shown in Table 4, half of the Canadian firms are using one the BPs mentioned in the SAT survey, of which three quarters are innovative. In contrast, among non-users of BPs, the innovation rate is only one third.

Table 4. Innovation and business practices (BP) use

\begin{tabular}{lcc|c}
\hline & $\begin{array}{c}\text { Using selected } \\
\text { business practices } \\
\text { (as defined by STC) }\end{array}$ & $\begin{array}{c}\text { Not using selected } \\
\text { business practices }\end{array}$ & Total \\
\hline Innovative firms & $37 \%$ & $18 \%$ & $55 \%$ \\
Non-innovative firms & $11 \%$ & $34 \%$ & $45 \%$ \\
\hline Total & $48 \%$ & $52 \%$ & $100 \%$ \\
\hline
\end{tabular}

Source: OECD/Statistics Canada analysis of Statistics Canada's Survey of Advanced Technology

This more pronounced discriminating role for BPs compared to ATs may be due to a number of factors. Before considering them, it is worth examining how robust are these correlations to accounting for multiple business features simultaneously. The first logistic (logit) regression results in Table 5 confirm the strength of these relationships across different specifications. 
Table 5. Innovation explained by technology and business practice usage

Coefficients from logistic regression with Innovation as dependent variable

\begin{tabular}{|c|c|c|c|c|c|c|c|}
\hline & $\begin{array}{l}\text { Innovation } \\
\text { (m1) }\end{array}$ & $\begin{array}{l}\text { Innovation } \\
\text { (m2) }\end{array}$ & $\begin{array}{l}\text { Innovation } \\
\text { (m3) }\end{array}$ & $\begin{array}{l}\text { Innovation } \\
\text { (m4) }\end{array}$ & $\begin{array}{l}\text { Innovation } \\
\text { (m5a) }\end{array}$ & $\begin{array}{l}\text { Product } \\
\text { innovation } \\
(\mathrm{m} 5 \mathrm{~b})\end{array}$ & $\begin{array}{l}\text { Business } \\
\text { process } \\
\text { innovation } \\
\text { (m5c) }\end{array}$ \\
\hline Intercept & $\begin{array}{c}0.06 \\
(0.09)\end{array}$ & $\begin{array}{l}-0.21^{*} \\
(0.09)\end{array}$ & $\begin{array}{l}-0.43^{\star \star \star} \\
(0.09)\end{array}$ & $\begin{array}{c}-0.44^{\star \star *} \\
(0.09)\end{array}$ & $\begin{array}{c}-0.26^{\star *} \\
(0.09)\end{array}$ & $\begin{array}{c}-1.14^{\star * *} \\
(0.09)\end{array}$ & $\begin{array}{c}-0.36^{* * *} \\
(0.09)\end{array}$ \\
\hline $\begin{array}{r}\text { Use of selected } \\
\text { advanced technologies }\end{array}$ & $\begin{array}{l}0.7^{* \star *} \\
(0.05)\end{array}$ & & $\begin{array}{l}0.57^{* * *} \\
(0.05)\end{array}$ & $\begin{array}{l}0.54^{* * *} \\
(0.05)\end{array}$ & & & \\
\hline $\begin{array}{r}\text { Use of selected } \\
\text { business practices }\end{array}$ & & $\begin{array}{l}1.15^{\star * *} \\
(0.05)\end{array}$ & $\begin{array}{l}1.07^{* \star *} \\
(0.05)\end{array}$ & $\begin{array}{l}1.04^{* * *} \\
(0.05)\end{array}$ & & & \\
\hline $\begin{array}{r}\text { Development of } \\
\text { advanced technology } \\
\end{array}$ & & & & $\begin{array}{c}1.27^{* * *} \\
(0.1)\end{array}$ & & & \\
\hline $\begin{array}{r}\text { Share of advanced } \\
\text { technologies planned to } \\
\text { be used within } 2 \text { years }\end{array}$ & & & & & $\begin{array}{c}9.14^{* \star *} \\
(0.59)\end{array}$ & $\begin{array}{l}5.17^{* * *} \\
(0.38)\end{array}$ & $\begin{array}{c}8.27^{* * *} \\
(0.53)\end{array}$ \\
\hline $\begin{array}{r}\text { Share of advanced } \\
\text { technologies used for less } \\
\text { than three years }\end{array}$ & & & & & $\begin{array}{c}13.35^{\star * *} \\
(0.89)\end{array}$ & $\begin{array}{l}6.93^{* * *} \\
(0.56)\end{array}$ & $\begin{array}{c}12.97^{\star \star *} \\
(0.82)\end{array}$ \\
\hline $\begin{array}{r}\text { Share of advanced } \\
\text { technologies used for } \\
\text { more than three years }\end{array}$ & & & & & $\begin{array}{c}6.8^{* * *} \\
(0.5)\end{array}$ & $\begin{array}{l}4.09^{* * *} \\
(0.36)\end{array}$ & $\begin{array}{l}6.12^{* * *} \\
(0.46)\end{array}$ \\
\hline Size FE & Yes & Yes & Yes & Yes & Yes & Yes & Yes \\
\hline Country of control FE & Yes & Yes & Yes & Yes & Yes & Yes & Yes \\
\hline Outsourcing FE & Yes & Yes & Yes & Yes & Yes & Yes & Yes \\
\hline Industry FE & Yes & Yes & Yes & Yes & Yes & Yes & Yes \\
\hline Number of observations & 7912 & 7912 & 7912 & 7912 & 7912 & 7912 & 7912 \\
\hline Nagelkerke R2 & 0.19 & 0.24 & 0.25 & 0.28 & 0.33 & 0.27 & 0.31 \\
\hline-2 Log Likelihood & 9258 & 8969 & 8851 & 8665 & 8247 & 8849 & 8691 \\
\hline
\end{tabular}

Note: $* * *$ : p-value $<=0.001 ; * *: 0.001<$ p-value $<=0.01 ; *: 0.01<$ p-value $<=0.05$.

Source: OECD/Statistics Canada analysis of Statistics Canada's Survey of Advanced Technology.

Models $\mathrm{m} 1$ and $\mathrm{m} 2$ validate the previous findings controlling for size, industry and other characteristics. An AT using firm is about twice as likely to innovate than a non AT user $\left(e^{0.7}\right)$, while a BP user is three times as likely $\left(e^{1.15}\right)$. These associations are almost as strong when accounting for both AT and BP use in the same specification (m3), and when the development of technologies ${ }^{28}$ is also controlled for $(\mathrm{m} 4)$.

As it might be expected, recent technology implementations are more correlated with innovation than older implementation. In addition, planning to use new technologies is more correlated with current innovation than using technologies for more than three years (m5a). This may be explained by the possibility that the reported innovation is the actual adoption of an AT. The correlation between recent innovation behaviour and expected future AT adoption signals that there may be a link between innovations at the firm level aimed at equipping itself to be prepared to adopt ATs in the future.

It is interesting to compare this pattern for product and business process innovations (see $\mathrm{m} 5 \mathrm{~b}$ and $\mathrm{m} 5 \mathrm{c}$ ). While the qualitative result is the same, the link between AT adoption and innovation is more acute for business process innovations. Indeed a majority of ATs presented relate to business process so it is not surprising that the timing of their adoption coincides with reported innovation. There is strong indication as well of planned AT adoption being closely related to recent process more than product innovation. 


\subsection{The link between innovation and different types of AT and BPs.}

The previous results treat all ATs and BPs as homogeneous. However the link with innovation may vary by type of AT and BPs, and this link may as before differ by type of innovation.

The relationship between the two main types of innovation (product and business innovation) and the seven factors is estimated using logistic regressions (Table $6-\mathrm{m} 1$ to $\mathrm{m} 3$ ). The use of logistics software technologies (factor 1), geomatics and geospatial technologies (factor 4), bio-and-environmental technologies (factor 5) and software and infrastructure as a service (factor 6) appear to correlate positively with both product and business process innovation (regressions $\mathrm{m} 1$ to $\mathrm{m} 3$ ). Furthermore, management practices and tools (factor 2) have the most visible connection with innovation, as shown in the previous section.

In models $\mathrm{m} 4$ to $\mathrm{m} 9$, the variables measuring the ATBP factor scores are replaced with technology and business practice domains as defined by Statistics Canada in the SAT survey (see Annex 2 for more details on the composition of the different domains), to show very similar results. The use of selected business practices (BPs) is correlated with the use of advanced technologies, in particular with the manufacturing-related technologies. Therefore, introducing business practices in the regressions reduces the coefficients associated to ATs (see regressions $\mathrm{m} 4$ to $\mathrm{m} 6$ versus $\mathrm{m} 7$ to $\mathrm{m} 9$ ). This is particularly the case for manufacturing technologies: coefficients associated to factor 3 (automated production process technologies) are not significant, as well as coefficient for "advanced processing and fabrication technologies" in regression 7 to 9 . This absence of significant relationship should be interpreted with care as the correlation between factors 2 and 3 is relatively high (see Table 7). As previously shown, industries making intense use of "management practices and tools" also tend to have high scores of automated production process technologies (see Figure 3).

The impact of using advanced technologies and business practices is higher on business process innovation than product innovation. This is true for all technologies and practices except additive and micro manufacturing technologies (factor 7) where the impact is positive on product innovation and not significant on business process innovation.

Contrary to what we found for using advanced technologies, developing them have a higher impact on product innovation than on business process innovation. This result suggests that the development of technologies might be slightly more oriented towards the introduction of new products. This result is principally driven by technologies other than nanotechnologies and biotechnologies, as the presence of the latter in the broad sample is limited and therefore not too precisely estimated. 
Table 6. The link between innovation and ATBPs

Coefficients from logistic regression with Innovation by type as dependent variables

\begin{tabular}{|c|c|c|c|c|c|c|c|c|c|c|}
\hline & & $\begin{array}{l}\text { Total } \\
\text { innovation } \\
\text { (m1) }\end{array}$ & $\begin{array}{l}\text { Product } \\
\text { innovation } \\
\text { (m2) }\end{array}$ & $\begin{array}{l}\text { Business } \\
\text { process } \\
\text { innovation } \\
\text { (m3) }\end{array}$ & $\begin{array}{l}\text { Total } \\
\text { innovation } \\
(\mathrm{m} 4)\end{array}$ & $\begin{array}{l}\text { Product } \\
\text { innovation } \\
\text { (m5) }\end{array}$ & $\begin{array}{l}\text { Business } \\
\text { process } \\
\text { innovation } \\
\text { (m6) }\end{array}$ & $\begin{array}{l}\text { Total } \\
\text { innovation } \\
\text { (m7) }\end{array}$ & $\begin{array}{l}\text { Product } \\
\text { innovation } \\
(\mathrm{m} 8)\end{array}$ & $\begin{array}{l}\text { Business } \\
\text { process } \\
\text { innovation } \\
\text { (m9) }\end{array}$ \\
\hline & Intercept & $\begin{array}{l}0.68^{\star \star \star} \\
(0.09)\end{array}$ & $\begin{array}{c}-0.59^{\star \star *} \\
(0.09)\end{array}$ & $\begin{array}{c}0.53^{\star \star \star} \\
(0.09)\end{array}$ & $\begin{array}{l}-0.16 \\
(0.09)\end{array}$ & $\begin{array}{l}-1.1^{* * *} \\
(0.09)\end{array}$ & $\begin{array}{l}-0.27^{* *} \\
(0.09)\end{array}$ & $\begin{array}{c}-0.54^{* * *} \\
(0.1)\end{array}$ & $\begin{array}{c}-1.37^{* \star *} \\
(0.09)\end{array}$ & $\begin{array}{c}-0.64^{* * *} \\
(0.09)\end{array}$ \\
\hline \multirow{7}{*}{ 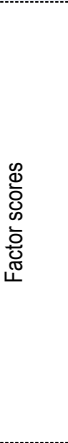 } & Factor 1: Logistics software technologies (LST) & $\begin{array}{l}1.37^{* * *} \\
(0.12)\end{array}$ & $\begin{array}{c}0.57^{* \star *} \\
(0.09)\end{array}$ & $\begin{array}{l}1.28^{* * *} \\
(0.11)\end{array}$ & & & & & & \\
\hline & $\begin{array}{l}\text { Factor 2: Management practices and tools } \\
\text { (MPT) }\end{array}$ & $\begin{array}{l}3.44^{* * *} \\
(0.14)\end{array}$ & $\begin{array}{c}2.27^{* * *} \\
(0.11)\end{array}$ & $\begin{array}{l}3.09^{* * *} \\
(0.13)\end{array}$ & & & & & & \\
\hline & $\begin{array}{r}\text { Factor 3: Automated production process } \\
\text { technologies (APPT) }\end{array}$ & $\begin{array}{l}0.15 \\
(0.21)\end{array}$ & $\begin{array}{l}-0.17 \\
(0.15)\end{array}$ & $\begin{array}{l}0.12 \\
(0.19)\end{array}$ & & & & & & \\
\hline & $\begin{array}{r}\text { Factor 4: Geomatics and geospatial } \\
\text { technologies (GGT) }\end{array}$ & $\begin{array}{l}0.66^{* * *} \\
(0.16)\end{array}$ & $\begin{array}{l}0.39^{* *} \\
(0.13)\end{array}$ & $\begin{array}{l}0.73^{* * *} \\
(0.15)\end{array}$ & & & & & & \\
\hline & $\begin{array}{r}\text { Factor 5: Bio-and-environmental technologies } \\
\text { (BBT) }\end{array}$ & $\begin{array}{l}0.99^{* * *} \\
(0.19)\end{array}$ & $\begin{array}{l}0.43^{* *} \\
(0.14)\end{array}$ & $\begin{array}{l}1.07^{\star \star \star} \\
(0.18)\end{array}$ & & & & & & \\
\hline & $\begin{array}{r}\text { Factor 6: Software and infrastructure as a } \\
\text { service (SIAS) }\end{array}$ & $\begin{array}{l}1^{\star \star *} \\
(0.12)\end{array}$ & $\begin{array}{l}0.74^{* \star *} \\
(0.1)\end{array}$ & $\begin{array}{l}0.95^{\star \star \star} \\
(0.11)\end{array}$ & & & & & & \\
\hline & $\begin{array}{r}\text { Factor 7: Additive and micro manufacturing } \\
\text { technologies (AMT) }\end{array}$ & $\begin{array}{c}0.82 \\
(0.47)\end{array}$ & $\begin{array}{l}0.98^{* *} \\
(0.31)\end{array}$ & $\begin{array}{l}0.7 \\
(0.4)\end{array}$ & & & & & & \\
\hline \multirow{9}{*}{ 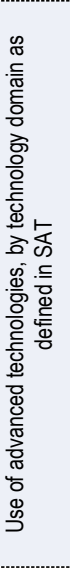 } & $\begin{array}{r}\text { Advanced material handling, supply chain and } \\
\text { logistics technologies }\end{array}$ & & & & $\begin{array}{l}0.58^{* \star \star} \\
(0.06)\end{array}$ & $\begin{array}{c}0.35^{\star * *} \\
(0.06)\end{array}$ & $\begin{array}{l}0.57^{* * *} \\
(0.06)\end{array}$ & $\begin{array}{l}0.44^{* * *} \\
(0.07)\end{array}$ & $\begin{array}{c}0.21^{* * *} \\
(0.06)\end{array}$ & $\begin{array}{c}0.43^{* * *} \\
(0.06)\end{array}$ \\
\hline & Advanced business intelligence technologies & & & & $\begin{array}{l}0.69^{\star \star *} \\
(0.07)\end{array}$ & $\begin{array}{l}0.4^{* \star *} \\
(0.06)\end{array}$ & $\begin{array}{l}0.63^{* \star *} \\
(0.07)\end{array}$ & $\begin{array}{l}0.57^{\star \star *} \\
(0.07)\end{array}$ & $\begin{array}{l}0.29^{* * *} \\
(0.06)\end{array}$ & $\begin{array}{l}0.51^{* * *} \\
(0.07)\end{array}$ \\
\hline & $\begin{array}{r}\text { Advanced design and information control } \\
\text { technologies }\end{array}$ & & & & $\begin{array}{l}0.62^{* * *} \\
(0.06)\end{array}$ & $\begin{array}{l}0.43^{* * *} \\
(0.06)\end{array}$ & $\begin{array}{l}0.6^{* * *} \\
(0.06)\end{array}$ & $\begin{array}{l}0.36^{* * *} \\
(0.07)\end{array}$ & $\begin{array}{l}0.2^{* *} \\
(0.06)\end{array}$ & $\begin{array}{l}0.36^{* * *} \\
(0.06)\end{array}$ \\
\hline & $\begin{array}{r}\text { Advanced processing and fabrication } \\
\text { technologies }\end{array}$ & & & & $\begin{array}{l}0.36^{\star * \star} \\
(0.09)\end{array}$ & $\begin{array}{l}0.29^{* * *} \\
(0.08)\end{array}$ & $\begin{array}{l}0.37^{* * *} \\
(0.08)\end{array}$ & $\begin{array}{c}0.1 \\
(0.1)\end{array}$ & $\begin{array}{c}0.08 \\
(0.08)\end{array}$ & $\begin{array}{c}0.13 \\
(0.09)\end{array}$ \\
\hline & Green technologies & & & & $\begin{array}{l}0.48^{\star \star \star} \\
(0.1)\end{array}$ & $\begin{array}{l}0.28^{* \star *} \\
(0.08)\end{array}$ & $\begin{array}{l}0.5^{\star \star \star} \\
(0.09)\end{array}$ & $\begin{array}{l}0.3^{* *} \\
(0.1)\end{array}$ & $\begin{array}{c}0.14 \\
(0.08)\end{array}$ & $\begin{array}{c}0.33^{* \star *} \\
(0.1)\end{array}$ \\
\hline & Geomatics or geospatial technologies & & & & $\begin{array}{l}0.44^{* * *} \\
(0.09)\end{array}$ & $\begin{array}{l}0.24^{* *} \\
(0.08)\end{array}$ & $\begin{array}{l}0.43^{* * *} \\
(0.08)\end{array}$ & $\begin{array}{l}0.31^{* * *} \\
(0.09)\end{array}$ & $\begin{array}{c}0.14 \\
(0.08)\end{array}$ & $\begin{array}{l}0.32^{* * *} \\
(0.09)\end{array}$ \\
\hline & Nanotechnologies & & & & $\begin{array}{c}0.56 \\
(0.73)\end{array}$ & $\begin{array}{l}1.32^{*} \\
(0.59)\end{array}$ & $\begin{array}{c}0.36 \\
(0.63)\end{array}$ & $\begin{array}{l}0.47 \\
(0.79)\end{array}$ & $\begin{array}{l}1.18 \\
(0.64)\end{array}$ & $\begin{array}{c}0.18 \\
(0.68)\end{array}$ \\
\hline & Biotechnologies & & & & $\begin{array}{c}0.57 \\
(0.31)\end{array}$ & $\begin{array}{l}0.51^{*} \\
(0.24)\end{array}$ & $\begin{array}{c}0.24 \\
(0.27)\end{array}$ & $\begin{array}{c}0.34 \\
(0.32)\end{array}$ & $\begin{array}{l}0.48^{*} \\
(0.24)\end{array}$ & $\begin{array}{c}0.02 \\
(0.28)\end{array}$ \\
\hline & Bioproducts & & & & $\begin{array}{l}0.52^{\star *} \\
(0.18)\end{array}$ & $\begin{array}{l}0.34^{*} \\
(0.14)\end{array}$ & $\begin{array}{l}0.6^{\star * *} \\
(0.17)\end{array}$ & $\begin{array}{l}0.38^{*} \\
(0.19)\end{array}$ & $\begin{array}{c}0.26 \\
(0.15)\end{array}$ & $\begin{array}{l}0.48^{\star *} \\
(0.18)\end{array}$ \\
\hline \multirow{5}{*}{ 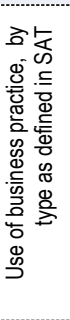 } & Collaboration practices & & & & & & & $\begin{array}{l}0.95^{* * *} \\
(0.09)\end{array}$ & $\begin{array}{c}0.52^{* \star *} \\
(0.07)\end{array}$ & $\begin{array}{l}0.86^{* * *} \\
(0.08)\end{array}$ \\
\hline & $\begin{array}{r}\text { Manufacturing and control management } \\
\text { practices }\end{array}$ & & & & & & & $\begin{array}{l}0.64^{\star \star \star} \\
(0.07)\end{array}$ & $\begin{array}{l}0.34^{* \star *} \\
(0.07)\end{array}$ & $\begin{array}{l}0.59^{\star \star *} \\
(0.07)\end{array}$ \\
\hline & Quality management practices & & & & & & & $\begin{array}{l}0.46^{\star \star \star} \\
(0.07)\end{array}$ & $\begin{array}{l}0.31^{* \star *} \\
(0.06)\end{array}$ & $\begin{array}{l}0.48^{\star \star *} \\
(0.07)\end{array}$ \\
\hline & Product development practices & & & & & & & $\begin{array}{l}0.9^{\star \star \star} \\
(0.11)\end{array}$ & $\begin{array}{l}0.88^{\star \star *} \\
(0.08)\end{array}$ & $\begin{array}{l}0.6^{* * *} \\
(0.09)\end{array}$ \\
\hline & Other practices & & & & & & & $\begin{array}{l}0.69^{* * *} \\
(0.12)\end{array}$ & $\begin{array}{l}0.44^{\star \star *} \\
(0.08)\end{array}$ & $\begin{array}{c}0.67^{* * *} \\
(0.1)\end{array}$ \\
\hline \multirow{4}{*}{ 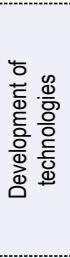 } & Development of advanced technologies & $\begin{array}{l}0.62^{* * *} \\
(0.11)\end{array}$ & $\begin{array}{l}0.68^{* * *} \\
(0.08)\end{array}$ & $\begin{array}{c}0.49^{\star * *} \\
(0.1)\end{array}$ & & & & & & \\
\hline & $\begin{array}{l}\text { Development of advanced technologies other } \\
\text { than bio and nanotechnologies }\end{array}$ & & & & $\begin{array}{l}0.75^{\star \star *} \\
(0.12)\end{array}$ & $\begin{array}{l}0.8^{\star \star *} \\
(0.09)\end{array}$ & $\begin{array}{l}0.62^{* * *} \\
(0.1)\end{array}$ & $\begin{array}{l}0.51^{* \star *} \\
(0.12)\end{array}$ & $\begin{array}{l}0.62^{* * *} \\
(0.09)\end{array}$ & $\begin{array}{l}0.4^{\star \star \star} \\
(0.11)\end{array}$ \\
\hline & Development of biotechnologies & & & & $\begin{array}{l}0.73^{\star *} \\
(0.27)\end{array}$ & $\begin{array}{l}0.51^{*} \\
(0.22)\end{array}$ & $\begin{array}{l}0.54^{*} \\
(0.25)\end{array}$ & $\begin{array}{c}0.32 \\
(0.29)\end{array}$ & $\begin{array}{c}0.21 \\
(0.22)\end{array}$ & $\begin{array}{c}0.14 \\
(0.26)\end{array}$ \\
\hline & Development of nanotechnologies & & & & $\begin{array}{c}0.56 \\
(1)\end{array}$ & $\begin{array}{l}-0.47 \\
(0.66)\end{array}$ & $\begin{array}{c}0.74 \\
(0.84)\end{array}$ & $\begin{array}{l}-0.24 \\
(1.03)\end{array}$ & $\begin{array}{l}-0.86 \\
(0.71)\end{array}$ & $\begin{array}{c}0.3 \\
(0.88)\end{array}$ \\
\hline \multirow{7}{*}{ 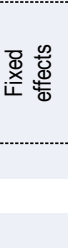 } & Size & Yes & Yes & Yes & Yes & Yes & Yes & Yes & Yes & Yes \\
\hline & Domestic/foreign-owned & Yes & Yes & Yes & Yes & Yes & Yes & Yes & Yes & Yes \\
\hline & Outsourced activities & Yes & Yes & Yes & Yes & Yes & Yes & Yes & Yes & Yes \\
\hline & Industry & Yes & Yes & Yes & Yes & Yes & Yes & Yes & Yes & Yes \\
\hline & $N$ & 7912 & 7912 & 7912 & 7912 & 7912 & 7912 & 7912 & 7912 & 7912 \\
\hline & -2 Log Likelihood & 8092 & 8594 & 8580 & 8466 & 8904 & 8932 & 7825 & 8432 & 8327 \\
\hline & Nagelkerke R2 & 0.35 & 0.30 & 0.32 & 0.30 & 0.26 & 0.28 & 0.39 & 0.33 & 0.35 \\
\hline
\end{tabular}

Note: $* * *$ : p-value $<=0.001 ; * *: 0.001<$ p-value $<=0.01 ; *: 0.01<$ p-value $<=0.05$.

Source: OECD/Statistics Canada analysis of Statistics Canada's Survey of Advanced Technology. 
Table 7. Correlation coefficient between factor scores

\begin{tabular}{|c|c|c|c|c|c|c|c|}
\hline & $\begin{array}{l}\text { Factor 1: } \\
\text { Logistics } \\
\text { software } \\
\text { technologies }\end{array}$ & $\begin{array}{l}\text { Factor 2: } \\
\text { Management } \\
\text { practices and } \\
\text { tools }\end{array}$ & $\begin{array}{c}\text { Factor 3: } \\
\text { Automated } \\
\text { production } \\
\text { process } \\
\text { technologies }\end{array}$ & $\begin{array}{c}\text { Factor 4: } \\
\text { Geomatics } \\
\text { and geospatial } \\
\text { technologies }\end{array}$ & $\begin{array}{l}\text { Factor 5: Bio- } \\
\text { and- } \\
\text { environmental } \\
\text { technologies }\end{array}$ & $\begin{array}{c}\text { Factor 6: } \\
\text { Software and } \\
\text { infrastructure } \\
\text { as a service }\end{array}$ & $\begin{array}{c}\text { Factor } 7: \\
\text { Additive and } \\
\text { micro } \\
\text { manufacturing } \\
\text { technologies }\end{array}$ \\
\hline $\begin{array}{l}\text { Factor 1: Logistics } \\
\text { software } \\
\text { technologies }\end{array}$ & 1.00 & & & & & & \\
\hline $\begin{array}{l}\text { Factor 2: } \\
\text { Management } \\
\text { practices and tools }\end{array}$ & 0.27 & 1.00 & & & & & \\
\hline $\begin{array}{l}\text { Factor } 3 \text { : } \\
\text { Automated } \\
\text { production process } \\
\text { technologies }\end{array}$ & 0.24 & 0.43 & 1.00 & & & & \\
\hline $\begin{array}{l}\text { Factor 4: } \\
\text { Geomatics and } \\
\text { geospatial } \\
\text { technologies }\end{array}$ & 0.03 & -0.07 & -0.15 & 1.00 & & & \\
\hline $\begin{array}{l}\text { Factor 5: Bio-and- } \\
\text { environmental } \\
\text { technologies }\end{array}$ & 0.08 & 0.11 & 0.12 & 0.11 & 1.00 & & \\
\hline $\begin{array}{l}\text { Factor 6: Software } \\
\text { and infrastructure } \\
\text { as a service }\end{array}$ & 0.08 & -0.03 & -0.06 & 0.13 & 0.00 & 1.00 & \\
\hline $\begin{array}{l}\text { Factor } 7 \text { : Additive } \\
\text { and micro } \\
\text { manufacturing } \\
\text { technologies }\end{array}$ & -0.05 & 0.06 & 0.18 & 0.00 & -0.04 & 0.03 & 1.00 \\
\hline
\end{tabular}

Source: OECD/Statistics Canada analysis of Statistics Canada's Survey of Advanced Technology.

\section{Concluding remarks}

\subsection{Overview of key findlings}

This report has analysed the patterns of advanced technology and business practices (ATBP) among Canadian firms within the scope of STC's 2014 Survey of Advanced Technology.

The mapping of high dimensional ATBP portfolios via factor analysis has revealed seven main categories of ATBP specialisation: logistics software technologies (LST); management practices and tools (MPT); automated production process technologies (APPT); geomatics and geospatial technologies (GGT); bio-and-environmental technologies (BBT); software and infrastructure as a service (SIAS); and additive and micro manufacturing technologies (AMMT). We have found strong evidence of complementarity across some of these, in particular MPTs with LSTs and APPTs. 
We have found the rate of use of ATBPs to be generally positively correlated to the size of firms, especially in the area of automated production process technologies where scale appears to be very important, and with the exception of software and infrastructure as a service technologies (including cloud computing), which are just as much diffused in small as in large firms. This underlines the attractiveness of such technologies for SMEs and their role in supporting potential scaling up. Foreign-controlled firms and firms making use of outsourcing are, in most case, more likely to use ATBPs.

Characterising industries by ATBP use patterns provides a complementary view of the standard classification systems for industries that are mainly informed by the type of goods and services delivered rather than the processes used to produce them. We find the professional services industry to share considerable similarities with resource intensive industries, which may be explained by their weight in the demand for professional services in Canada. We are able to produce a classification that is entirely driven by technology use across different domains, as opposed to development indicators such as R\&D or patenting. The correlation between R\&D intensity and technology is good in manufacturing industries and very low in services. Most non-manufacturing sectors are low R\&D intensive whereas many of them appear as technology-intensive sectors. This confirms the limitations of using R\&D measures for building technology taxonomies of industries.

We found that innovation is highly correlated with the use of business practices and advanced technologies. Regression results suggest that using advanced technologies doubles the odds of innovating. The odds of innovating are trebled for business practice users. The results are also indicative of some complementary between the two vis a vis explaining innovation, as the effect of one does not get fully cancelled by the presence of the other. A positive relationship is also found between the development of technologies and innovation, especially for products.

Additional insights are also provided about the timing of technology adoption and innovation. We find a strong connection between the timing of technology adoption by firms and their reporting of process innovations. Innovating companies also appear more likely to consider the adoption of ATs if they have not done so already.

\subsection{Potential implications for follow on work}

Our analysis brings up a range of potential considerations for further reflection. In order to qualify our results, we should note that we are not able to assess at this point to what extent the results would have differed if a different list of technologies and business practices had been presented to respondents. We note that there might be a slight orientation in the 2014 SAT towards identifying AT and BP use of particular relevance in manufacturing, resource intensive and wholesale industries, reflecting internal and stakeholder interests with whom STC engaged in intensive consultation. Considering AT and BP use in a broader set of industries, especially within services, might require further investigation of what ATs and BPs might be also relevant to ask about.

The survey could not have possibly covered all relevant advanced technologies as it would have been too long. However, technologies and industries were chosen aiming to cover the value chain from input to output (i.e. Resource industries to retail industries for instance) with technologies that supported the production value chain (Automation technologies, management technologies and logistics technologies), and in doing so, seeking a compromise to cover technologies relating to different industry groups (manufacturing and services). 
A related concern might apply in the case of technology domains that have attracted considerable policy interest in recent years, namely biotechnology and nanotechnology. By characterising those in the survey as emerging technologies, respondents may have raised the bar about what they believed they were being asked about. An alternative conclusion is that general surveys are not fully suited to capture more "niche-based" technological activity. Targeted approaches would be required if the objective is full enumeration. We also entertain the possibility that some of the co-occurrence patterns of AT and BP use might be related to the order in which they were presented as well as how they were grouped.

Notwithstanding those potential caveats, the SAT survey and analysis based on it have considerable power to inform how to address the current disjoint approach to assessing the role of innovation, technology and management when explaining business economic performance. There are opportunities for deepening the work within the Canadian context by linking SAT with economic performance data in order to assess the impact of technology and innovation. It should also be possible to analyse variables on business internal capabilities and external factors favouring technology adoption and innovation.

The recent launch of the revised Oslo Manual and the widespread focus on digitalisation and digital based innovation provide opportunities to reflect within relevant OECD working parties on the findings presented in this study, helping identify new data collection and analysis strategies to meet user needs. It is hoped that this analysis will motivate interest in refining the SAT approach further and applying it in other national contexts in a coordinated fashion. 


\section{Notes}

${ }^{1}$ The measurement of ICT use in business falls under the responsibility of the OECD Working Party on Measurement and Analysis in the Digital Economy (MADE). See https://www.oecd.org/sti/ieconomy/ICT-Model-Survey-Usage-Businesses.pdf and http://oe.cd/bus.

${ }^{2}$ See OECD Key Biotechnology Indicators http://oe.cd/kbi

${ }^{3}$ See OECD Key Nanotechnology Indicators http://oe.cd/kni

${ }^{4}$ Innovation activities may also include engineering, design and other creative work activities; marketing and brand equity activities; IP-related activities; employee training activities; software development and database activities; activities related to the acquisition or lease of tangible assets; and innovation management activities (OECD, 2018: § 4.8).

${ }^{5}$ See Boyer et al. (1996, p. 300) for a summary of the AT typologies defined in these studies.

${ }^{6}$ According to this context-dependent model, a given management style or business practice cannot dominate other styles or practices and cannot be modelled quantitatively as an intangible asset.

7 See www.oecd.org/going-digital and the OECD Committee for Scientific and Technological Policy (CSTP) synthesis report on "The Digitalisation of Science, Technology and Innovation: Key Developments and Policies" (OECD, 2020).

${ }^{8}$ Further information on previous editions is available at http://www23.statcan.gc.ca/imdb/p2SV.pl?Function=getInstanceList\&Id=164083

9 http://www23.statcan.gc.ca/imdb/p2SV.pl?Function=getSurvey \&SDDS=4223

10 Definitions can be found on the STC website: http://www23.statcan.gc.ca/imdb/p3Instr.pl?Function=assembleInstr\&a=1\&\&lang=en\&Item Id=1

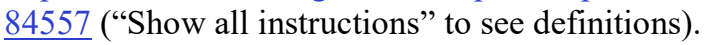

${ }^{11}$ The survey guidance indicates the following: "For the purposes of this survey, the technology that is considered to be advanced is found in Questions 1, 8, 15, 16 and 23."

12 The term emergent is more often associated to technologies whose implementation is still in the process of being demonstrated. Such a perspective would exclude in principle all the examples presented as emerging, as the use of biotechnology and nanotechnology is well advanced in several applications.

13 STC tables 27-10-0278-01, 27-10-0279-01, 27-10-0289-01, 27-10-0277-01, 27-10-0301-01, $27-$ 10-0296-01, 27-10-0290-01 and 27-10-0295-01. See also The Daily (Statistics Canada's official release bulletin) of 11 December 2015, https://www150.statcan.gc.ca/n1/dailyquotidien/151211/dq151211b-eng.htm.

14 Other than geomatics and geospatial technologies, nanotechnologies, biotechnologies and bioproducts.

15 Except for nanotechnologies, biotechnologies and bioproducts, only firms using advanced technologies can report that they have also developed some advanced technologies. Therefore, cases where firms are not using but are developing technologies are not captured.

16 STC tables 27-10-0316-01, 27-10-0314-01, 27-10-0317-01, 27-10-0313-01 and 27-10-0315-01. See also The Daily (Statistics Canada's official release bulletin) of 18 March 2016, https://www150.statcan.gc.ca/n1/daily-quotidien/160318/dq160318c-eng.htm.

${ }^{17}$ We use the term business process innovation used in the 2018 edition of the Oslo Manual although here it is based on data collected on the basis of the 2005 edition. This means that a firm that reports 
having introduced a process, organisational or marketing innovation (OM3 edition terms) is effectively categorised for the analysis as a business process innovative firm.

18 This analysis does not exploit all the rich content of the SAT survey and its numerous variables. Among others, the unused variables concern the objectives of adopting advanced technologies, the obstacles encountered when implementing them, the measures adopted to reduce these obstacles, the capital spent in these technologies, or the skill requirements and training expenses pertaining to their adoption. The survey form provides details about the various collected variables: http://www23.statcan.gc.ca/imdb/p3Instr.pl?Function=getInstrumentList\&Item Id=184557\&UL= $\underline{1 \mathrm{~V} \&}$

${ }^{19}$ See https://www150.statcan.gc.ca/n1/daily-quotidien/160318/dq160318c-cansim-eng.htm

${ }^{20}$ For instance, technology adoption rates are available by industry, as well as innovation rates, but not the proportions of firms using advanced technologies and innovating.

${ }^{21}$ This is the model currently adopted at OECD for the microBeRD project (oe.cd/microberd) and previously for the project on Innovation in firms (OECD, 2009).

${ }^{22}$ Other measures were envisaged, as the tetrachoric correlation coefficient (widely used in factor analyses with categorical variables), the simple matching coefficient (SMC) or the Phi coefficient. All these measures increase with the number of occurrences where both technologies are used.

${ }^{23}$ Suppose a sample of 100 firms. 8 firms are using technology A but not B; 8 are using B and not A; 4 are using both; and 80 are not using any of them. The Jaccard index will be equal to 0.2 $(=4 /(8+8+4))$. The other mentioned coefficients (tetrachoric, Phi, SMC) will be also counting firms where A and B are not used. For example, the SMC will be $0.84(=(80+4) / 100)$.

${ }^{24}$ While the scree plot of eigenvalues recommended choosing either four or seven, the additional information of the seven-factor solution is more meaningful and useful for the rest of the analysis.

${ }^{25}$ Note that the industry dimension is analysed in the following subsection.

26 In Hatzichronoglou (1997), manufacturing industries defined in the International Standard Industrial Classification (ISIC) Revision 2 are classified in five groups (high, medium-high, medium-low and low technology) according to their direct R\&D effort and a measure of acquired R\&D through purchases of intermediates and capital goods. OECD (2003b) is an update in ISIC Rev. 3, using direct R\&D intensity only as a proxy for technology intensity. Galindo-Rueda and Verger (2016) extends the taxonomy, explicitly named as $R \& D$ intensity taxonomy, to all ISIC Rev.4 industries including services.

${ }^{27}$ Nevertheless, some divergences may reflect country-specific specialisation as the R\&D taxonomy is based on industrial R\&D efforts averaged across OECD countries, while the technology data presented here only concern Canada [NB: we will provide here also STC/ANBERD information about specific Canadian R\&D intensity by industry].

28 This measure cannot be perfectly derived for all specific types of AT data, except for nanotechnologies, biotechnologies and bioproducts For these technologies, there is a dedicated question in SAT survey asking whether the firm is developing such technologies or not. For the other technologies, only firms using advanced technologies can report in a follow-up question whether they integrated these technologies by developing them (or by developing other advanced technologies). Therefore, this variable exclude cases where firms are not using but are developing technologies. For this reason, the difference in magnitude of both coefficients (associated to the use versus the development of technologies) should not be compared. 


\section{References}

Adler, P. S. (1988), “Managing Flexible Automation”, California Management Review, 30(3), 34-56.

Avram, M. G. (2014), “Advantages and Challenges of Adopting Cloud Computing from an Enterprise Perspective”, Procedia Technology, 12(12), 529-534.

Barge-Gil, A., M. J. Nieto and L. Santamaría (2011), "Hidden Innovators: The Role of Non-R\&D Activities", Technology Analysis \& Strategic Management, 23(4), 415-432.

Bloom, N., B. Eifert, A. Mahajan, D. J. McKenzie and J. Roberts (2011), "Does Management Matter? Evidence from India", Quarterly Journal of Economics, 128(1), 1-53.

Bloom, N., H. Schweiger and J. V. Reenen (2012), "The Land that Lean Manufacturing Forgot", Economics of Transition, 20(4), 593-635

Bloom, N., R., Sadun and J. V. Reenen (2016), "Management as a Technology", NBER Working Paper No. 22327, National Bureau of Economic Research.

Bloom, N., E. Brynjolfsson, L. Foster, R. S. Jarmin, M. Patnaik, I. Saporta-Eksten and J. V. Reenen (2017), "What Drives Differences in Management", NBER Working Paper No. 23300, National Bureau of Economic Research.

Boyer, K. K., P. T. Ward and G. K. Leong (1996), "Approaches to the Factory of the Future. An Empirical Taxonomy”, Journal of Operations Management, 14 (4): 297-313.

Boyer, K. K., G. K. Leong, P. T. Ward and L. J. Krajewski (1997), "Unlocking the Potential of Advanced Manufacturing Technologies”, Journal of Operations Management, 15(4), 331-347.

Bourke, J. and S. Roper (2016), “AMT Adoption and Innovation: An Investigation of Dynamic and Complementary Effects", Technovation, 55, 42-55.

Bruhn, M., D. S. Karlan and A. Schoar (2016), "The Impact of Consulting Services on Small and Medium Enterprises: Evidence from a Randomized Trial in Mexico", Journal of Political Economy, 126:2, 635-687.

Bülbül, H., N. Ömürbek, T. Paksoy and T. Bektaş (2013), “An Empirical Investigation of Advanced Manufacturing Technology Investment Patterns: Evidence from a Developing Country”, Journal of Engineering and Technology, 30(2), 136-156.

Cagliano, R. and G. Spina (2000), “Advanced Manufacturing Technologies and Strategically Flexible Production”, Journal of Operations Management, 18(2), 169-190.

Calvino, F., C. Criscuolo, L. Marcolin and M. Squicciarini (2018), "A taxonomy of digital intensive sectors", OECD Science, Technology and Industry Working Papers, No. 2018/14, OECD Publishing, Paris, https://doi.org/10.1787/f404736a-en.

Challis, D., D. Samson and B. Lawson (2002), "Integrated Manufacturing, Employee and Business Performance: Australian and New Zealand Evidence", International Journal of Production Research, 40(8), 1941-1964.

Cheng, Y., R. Matthiesen, S. Farooq, J. Johansen, H. Hu and L. Ma (2018), “The Evolution of Investment Patterns on Advanced Manufacturing Technology (AMT) in Manufacturing Operations: A Longitudinal Analysis", International Journal of Production Economics, 203, 239-253.

Chung, W. and M. Swink (2009), "Patterns of Advanced Manufacturing Technology Utilization and Manufacturing Capabilities", Production and Operations Management, 18(5), 533-545. 
Das, A., and J. Jayaram (2003), "Relative Importance of Contingency Variables for Advanced Manufacturing Technology", International Journal of Production Research, 41(18), 4429-4452.

Díaz, M. S., J. A. Machuca and M. J. Álvarez-Gil (2003), “A View of Developing Patterns of Investment in AMT through Empirical Taxonomies: New Evidence”, Journal of Operations Management, 21(5), 577-606.

Galindo-Rueda, F. and F. Verger (2016), "OECD Taxonomy of Economic Activities Based on R\&D Intensity”, OECD Science, Technology and Industry Working Papers, No. 2016/04, OECD Publishing, Paris, https://doi.org/10.1787/5jlv73sqqp8r-en.

Galindo-Rueda, F. and V. Millot (2015), "Measuring Design and its Role in Innovation", OECD Science, Technology and Industry Working Papers, No. 2015/01, OECD Publishing, Paris. http://dx.doi.org/10.1787/5js7p6lj6zq6-en.

Hatzichronoglou, T. (1997), "Revision of the High-Technology Sector and Product Classification", OECD Science, Technology and Industry Working Papers, No. 1997/02, OECD Publishing, Paris, http://dx.doi.org/10.1787/134337307632.

Hsu, P.-F., S. Ray and Y.-Y. Li-Hsieh (2014), "Examining Cloud Computing Adoption Intention, Pricing Mechanism, and Deployment Model", International Journal of Information Management, 34(4), 474488.

Jonsson, P. (2000), “An Empirical Taxonomy of Advanced Manufacturing Technology”, International Journal of Operations \& Production Management, 20(12), 1446-1476.

Khanchanapong, T., D. I. Prajogo, A. S. Sohal, B. Cooper, A. C. L. Yeung and T. C. E. Cheng (2014), "The Unique and Complementary Effects of Manufacturing Technologies and Lean Practices on Manufacturing Operational Performance", International Journal of Production Economics, 153, 191203.

Lei, D. and J. D. Goldhar (1991), "Computer-integrated Manufacturing (CIM): Redefining the Manufacturing Firm into a Global Service Business", International Journal of Operations \& Production Management, 11(10), 5-18.

Low, C., Y. Chen and M. Wu (2011), "Understanding the Determinants of Cloud Computing Adoption", Industrial Management and Data Systems, 111(7), 1006-1023.

Mansfield, E. (1993), "The Diffusion of Flexible Manufacturing Systems in Japan, Europe and the United States", Management Science, 39(2), 149-159.

Meredith, J. (1987), "The Strategic Advantage of the Factory of the Future", California Management Review, Vol. 29 No. 3, pp. 27-41.

OECD (2020), The Digitalisation of Science, Technology and Innovation: Key Developments and Policies, OECD Publishing, Paris, https://doi.org/10.1787/b9e4a2c0-en.

OECD (2019), Measuring the Digital Transformation: A Roadmap for the Future, OECD Publishing, Paris, https://doi.org/10.1787/9789264311992-en

OECD/Eurostat (2018), Oslo Manual 2018: Guidelines for Collecting, Reporting and Using Data on Innovation, 4th Edition, The Measurement of Scientific, Technological and Innovation Activities, OECD Publishing, Paris/Eurostat, Luxembourg, https://doi.org/10.1787/9789264304604-en.

OECD (2009), Innovation in Firms: A Microeconomic Perspective, OECD Publishing, Paris, https://doi.org/10.1787/9789264056213-en.

OECD (2003a), Measuring Knowledge Management in the Business Sector: First Steps, Paris: OECD. 
OECD (2003b), OECD Science, Technology and Industry Scoreboard 2003, OECD Publishing, Paris, http://dx.doi.org/10.1787/sti scoreboard-2003-en.

Oliveira, T. A. G. F. de, M. A. Thomas and M. Espadanal (2014), "Assessing the Determinants of Cloud Computing Adoption: An Analysis of the Manufacturing and Services Sectors", Information \& Management, 51(5), 497-510.

Rosenthal, L. (1984), "Progress Toward the Factory of the Future", Journal of Operations Management, 4 (3): 203-229.

Santamaría, L., M. J. Nieto and A. Barge-Gil (2009), "Beyond Formal R\&D: Taking Advantage of Other Sources of Innovation in Low- and Medium-Technology Industries", Research Policy, 38(3), 507517.

Saraph, J.V. and R.J. Sebastian (1992), "Human Resource Strategies for Effective Introduction of Advanced Manufacturing Technologies (AMT)”, Production and Inventory Management Journal, first quarter, 64-70.

Spiezia, V. (2011), “Are ICT Users More Innovative?: an Analysis of ICT-Enabled Innovation in OECD Firms", OECD Journal: Economic Studies, vol. 2011/1, https://doi.org/10.1787/eco studies-2011$5 \mathrm{~kg} 2 \mathrm{~d} 2 \mathrm{hkn} 6 \mathrm{vg}$.

Statistics Canada, Survey of Advanced Technology, tables on technology adoption, tables 27-10-027801, 27-10-0279-01, 27-10-0289-01, 27-10-0277-01, 27-10-0301-01, 27-10-0296-01, 27-10-0290-01 and 27-10-0295-01; tables on business practices, tables 27-10-0316-01, 27-10-0314-01, 27-10-031701, 27-10-0313-01 and 27-10-0315-01; and table 27-10-0318-01 on introduction of innovations.

Statistics Canada, The Daily (Statistics Canada's official release bulletin), 2016-03-18, Survey of Advanced Technology: Innovation and business practices, 2014, https://www150.statcan.gc.ca/n1/daily-quotidien/160318/dq160318c-eng.htm.

Statistics Canada, The Daily (Statistics Canada's official release bulletin), 2015-12-11, Survey of Advanced Technology, 2014, https://www150.statcan.gc.ca/n1/daily-quotidien/151211/dq151211beng.htm.

Sultan, N. A. (2011), "Reaching for the Cloud: How SMEs Can Manage", International Journal of Information Management, 31(3), 272-278.

Swamidass, P. M. and S. Kotha (1998), "Explaining Manufacturing Technology Use, Firm Size and Performance Using a Multidimensional View of Technology", Journal of Operations Management, 17(1), 23-37.

Zhou, H., G. K. Leong, P. Jonsson and C.-C. Sum (2009), “A Comparative Study of Advanced Manufacturing Technology and Manufacturing Infrastructure Investments in Singapore and Sweden", International Journal of Production Economics, 120(1), 42-53. 


\section{Annex. Additional tables and figures}

\section{Annex 1. List of industries covered in the SAT survey and this paper}

\begin{tabular}{|c|c|c|c|}
\hline $\begin{array}{l}\text { NAICS } \\
\text { code }\end{array}$ & Industry label & $\begin{array}{l}\text { NAICS } \\
\text { code }\end{array}$ & Industry label \\
\hline 113 & Forestry and logging & 415 & Motor vehicle merchant wholesalers \\
\hline 211 & Oil and gas extraction & 416 & Building material and supplies merchant wholesalers \\
\hline 212 & Mining and quarrying (except oil and gas) & 417 & Machinery, equipment and supplies merchant wholesalers \\
\hline 213 & Support activities for mining, and oil and gas extraction & 418 & Miscellaneous merchant wholesalers \\
\hline 221 & Utilities & 419 & B-to-B electronic markets, and agents and brokers \\
\hline 311 & Food manufacturing & 441 & Motor vehicle and parts dealers \\
\hline 312 & Beverage and tobacco product manufacturing & 442 & Furniture and home furnishings stores \\
\hline 313 & Textile mills & 443 & Electronics and appliance stores \\
\hline 314 & Textile product mills & 444 & Building material and garden equipment and supplies dealers \\
\hline 315 & Clothing manufacturing & 445 & Food and beverage stores \\
\hline 316 & Leather and allied product manufacturing & 446 & Health and personal care stores \\
\hline 321 & Wood product manufacturing & 447 & Gasoline stations \\
\hline 322 & Paper manufacturing & 448 & Clothing and clothing accessories stores \\
\hline 323 & Printing and related support activities & 451 & Sporting goods, hobby, book and music stores \\
\hline 324 & Petroleum and coal product manufacturing & 452 & General merchandise stores \\
\hline 325 & Chemical manufacturing & 453 & Miscellaneous store retailers \\
\hline 326 & Plastics and rubber products manufacturing & 454 & Non-store retailers \\
\hline 327 & Non-metallic mineral product manufacturing & 481 & Air transportation \\
\hline 331 & Primary metal manufacturing & 482 & Rail transportation \\
\hline 332 & Fabricated metal product manufacturing & 483 & Water transportation \\
\hline 333 & Machinery manufacturing & 484 & Truck transportation \\
\hline 334 & Computer and electronic product manufacturing & 485 & Transit and ground passenger transportation \\
\hline 335 & Electrical equipment, appliance and component & 486 & Pipeline transportation \\
\hline 336 & Transportation equipment manufacturing & 487 & Scenic and sightseeing transportation \\
\hline 337 & Furniture and related product manufacturing & 488 & Support activities for transportation \\
\hline 339 & Miscellaneous manufacturing & 491 & Postal service \\
\hline 411 & Farm product merchant wholesalers & 492 & Couriers and messengers \\
\hline 412 & Petroleum and petroleum products merchant wholesalers & 493 & Warehousing and storage \\
\hline 413 & Food, beverage and tobacco merchant wholesalers & 541 & Professional, scientific and technical services \\
\hline 414 & Personal and household goods merchant wholesalers & & \\
\hline
\end{tabular}


Annex 2. List of advanced technologies and business practices used in this paper

\begin{tabular}{|c|c|}
\hline ADVANCED TECHNOLOGIES & $\begin{array}{l}\text { DOMAINS AS } \\
\text { DEFINED BY } \\
\text { STATISTICS } \\
\text { CANADA }\end{array}$ \\
\hline \multicolumn{2}{|l|}{ Customer Relationship Management (CRM) software } \\
\hline \multicolumn{2}{|l|}{ Software for demand forecasting or demand planning } \\
\hline \multicolumn{2}{|l|}{ Transportation management system } \\
\hline \multicolumn{2}{|l|}{ Warehouse Management System (WMS) } \\
\hline \multicolumn{2}{|l|}{ Supply chain collaboration and visibility systems } \\
\hline \multirow{2}{*}{\multicolumn{2}{|c|}{$\begin{array}{l}\text { Automated Storage (AS) and Retrieval System (RS) } \\
\text { Automated products and parts identification (e.q. bar or QR coding) }\end{array}$}} \\
\hline & \\
\hline \multicolumn{2}{|l|}{ Radio frequency identification (RFID) } \\
\hline \multicolumn{2}{|l|}{ Executive dashboards for analytics or decision-making } \\
\hline \multicolumn{2}{|l|}{ Software for large-scale data processing (e.g., Hadoop) } \\
\hline \multicolumn{2}{|l|}{ Live stream processing technology or real-time monitoring } \\
\hline \multicolumn{2}{|l|}{ Software as a service (AaaS) (e.g., cloud computing - software) } \\
\hline \multicolumn{2}{|l|}{ Infrastructure as a service (laaS) (e.g., cloud computing - hardware) } \\
\hline \multicolumn{2}{|l|}{ Air or emission technologies } \\
\hline \multicolumn{2}{|l|}{ Energy technologies (e.g., ISO50000) } \\
\hline \multicolumn{2}{|l|}{ Water technologies } \\
\hline \multicolumn{2}{|l|}{ Waste technologies } \\
\hline \multicolumn{2}{|l|}{$\begin{array}{l}\text { Virtual Product Development or modelling software including Computer Aided Design (CAD), Computer Aided } \\
\text { Engineering (CAE), Computer Aided Manufacturing (CAM) }\end{array}$} \\
\hline \multicolumn{2}{|l|}{ Virtual manufacturing } \\
\hline \multicolumn{2}{|l|}{ Enterprise Resource Planning (ERP) } \\
\hline \multicolumn{2}{|l|}{ Manufacturing Execution System (MES) } \\
\hline \multicolumn{2}{|l|}{ Software integration of quality results with planning and control softwares } \\
\hline \multicolumn{2}{|l|}{ Manufacturing Resource Planning (MRP II) } \\
\hline \multicolumn{2}{|l|}{ Inter-company computer networks including Extranet and electronic data interchange (EDI) } \\
\hline \multicolumn{2}{|l|}{ Wireless communications for production } \\
\hline \multicolumn{2}{|l|}{ Sensor network and integration } \\
\hline \multicolumn{2}{|l|}{ Computer Integrated Manufacturing (CIM) } \\
\hline \multicolumn{2}{|l|}{$\begin{array}{l}\text { Automated systems for inspection (e.g., vision-based, laser-based, X-ray, high-definition (HD) camera or sensor- } \\
\text { based) }\end{array}$} \\
\hline Unmanned aerial system (e.g., drone) & \\
\hline Flexible Manufacturing Cells (FMC) or Flexible Manufacturing Systems (FMS) & \\
\hline Lasers used in materials processing (including surface modification) & \\
\hline Robot(s) with sensing or vision systems & \\
\hline Robot(s) without sensing or vision systems & \\
\hline 4-9 axis computer numerically controlled (CNC) machinery & \\
\hline Additive manufacturing including rapid prototyping for plastics and 3D printing for plastics & Advanced \\
\hline Additive manufacturing including rapid prototyping for metals and 3D printing for metals & Processing and \\
\hline $\begin{array}{l}\text { Additive manufacturing including rapid prototyping for materials other than plastics and metals, and 3D printing } \\
\text { other than plastics and metals }\end{array}$ & $\begin{array}{l}\text { Fabrication } \\
\text { Technologies }\end{array}$ \\
\hline Automated machinery for sorting, transporting or assembling parts & \\
\hline Plasma sputtering & \\
\hline Micro-manufacturing (e.g., micro-machining or micro-moulding) & \\
\hline Microelectromechanical Systems (MEMS) & \\
\hline
\end{tabular}




\section{ADVANCED TECHNOLOGIES}

CANADA

\begin{tabular}{|c|c|}
\hline Geographic information systems (GIS) & \multirow{6}{*}{$\begin{array}{l}\text { Geomatics or } \\
\text { Geospatial } \\
\text { technologies }\end{array}$} \\
\hline Global positioning system (GPS) (exclude personal use) & \\
\hline Remote sensing (RS) & \\
\hline Mobile device with geolocation capabilities & \\
\hline Web or wireless sensors & \\
\hline Spatial data infrastructure & \\
\hline Nanotechnologies & Nanotechnologies \\
\hline Biotechnologies & Biotechnologies \\
\hline Bioproducts & Bioproducts \\
\hline BUSINESS PRACTICES & $\begin{array}{l}\text { GROUPINGS AS } \\
\text { DEFINED BY } \\
\text { STATISTICS } \\
\text { CANADA }\end{array}$ \\
\hline Concurrent engineering (Simultaneous design) & \multirow{2}{*}{$\begin{array}{l}\text { Product } \\
\text { development } \\
\text { practices }\end{array}$} \\
\hline Cross-functional design teams & \\
\hline Electronic work order management & \multirow{4}{*}{$\begin{array}{l}\text { Manufacturing and } \\
\text { control } \\
\text { management } \\
\text { practices }\end{array}$} \\
\hline Distribution Resource Planning (DRP) & \\
\hline Lean manufacturing & \\
\hline Just-in-time (JIT) & \\
\hline \multicolumn{2}{|l|}{ Continuous improvement (including Total Quality Management (TQM)) } \\
\hline Business certification or certification renewals (e.g., ISO 9000, ISO 14000) & \multirow{5}{*}{$\begin{array}{l}\text { Quality } \\
\text { management } \\
\text { practices }\end{array}$} \\
\hline Statistical Process Control (SPC) & \\
\hline Quality Management System (QMS) & \\
\hline Quality Function Deployment (QFD) & \\
\hline 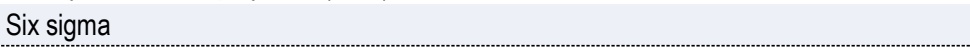 & \\
\hline \multicolumn{2}{|l|}{ Collaboration or strategic alliance with universities, technical institutes or colleges } \\
\hline Collaboration or strategic alliance with government research organizations and programs & \multirow{2}{*}{$\begin{array}{l}\text { Collaboration } \\
\text { practices }\end{array}$} \\
\hline Collaboration or strategic alliance with other companies & \\
\hline Competitive Technological Intelligence (CTI) and benchmarking & \multirow{3}{*}{ Other practices } \\
\hline Sustainable development strategy or environmental stewardship plan (ESP) & \\
\hline Product Data Management (PDM) or Life Cycle Management (LCM) & \\
\hline
\end{tabular}


Annex 3a. Adoption rates of technologies and business practices

Incidence of advanced technology use in Canadian firms

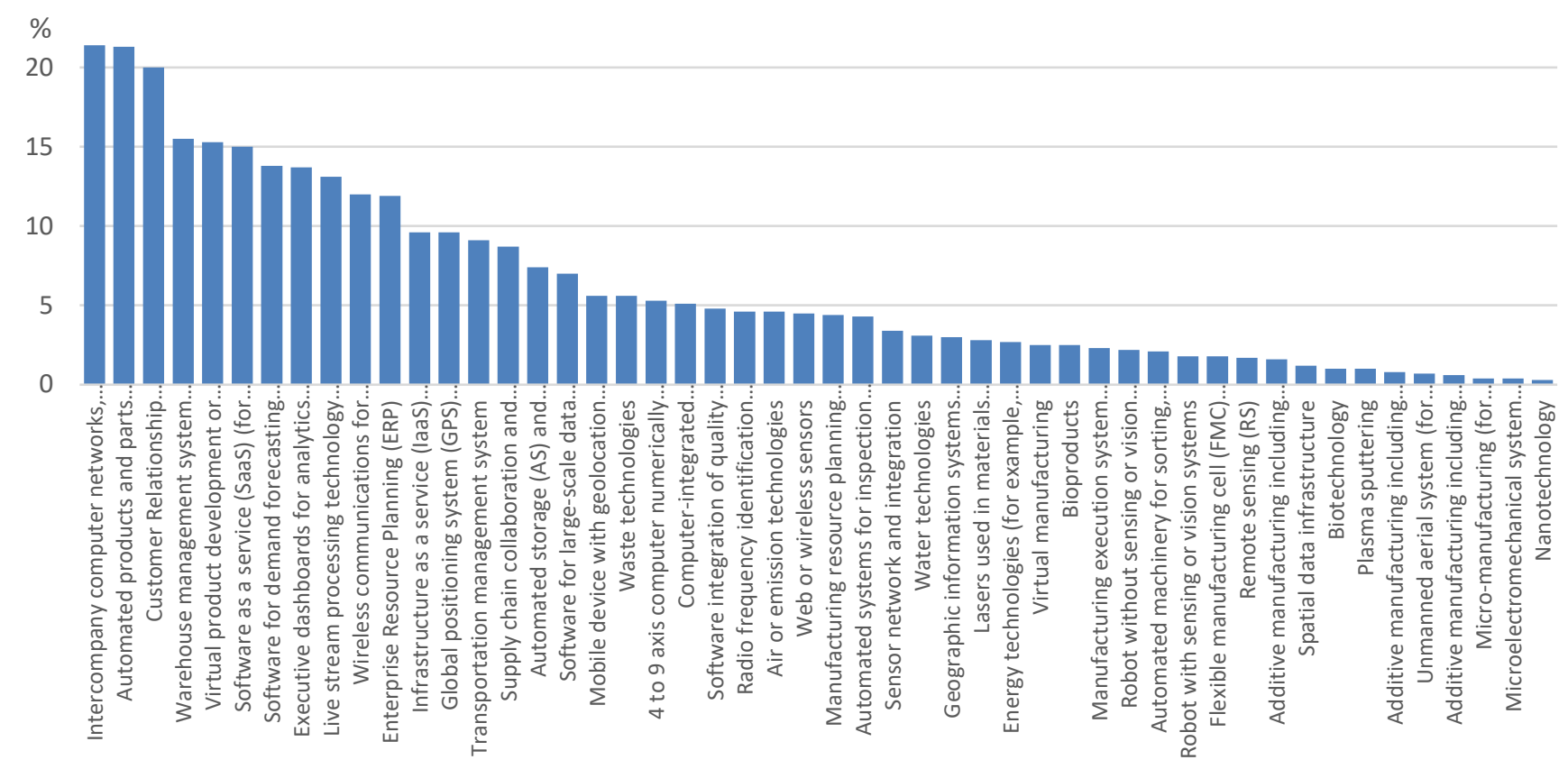

Incidence of business practice use in Canadian firms

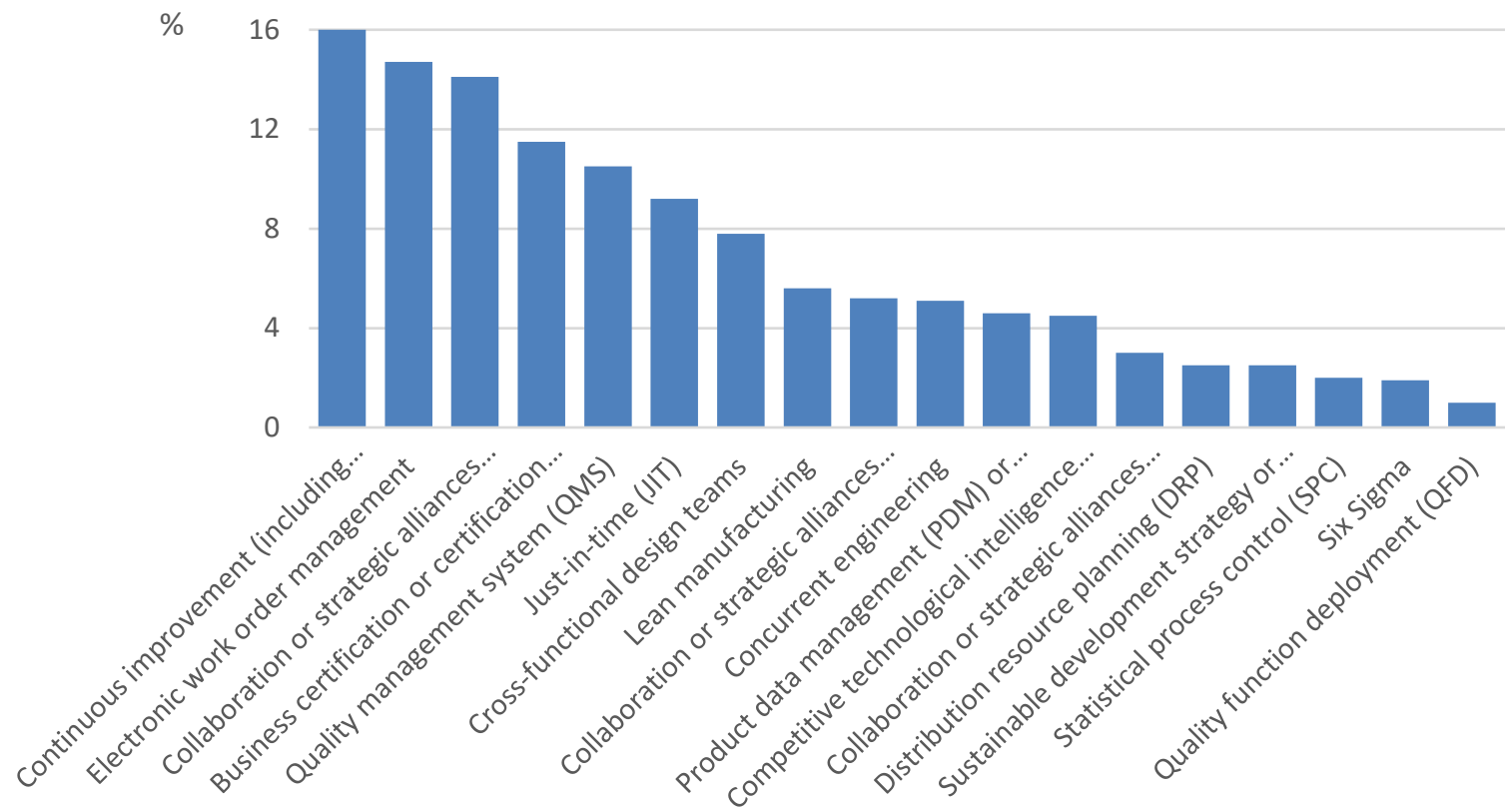

Source: Statistics Canada, Survey of Advanced Technology tables. 


\section{Annex 3b. Timing of adoption}

\begin{tabular}{|c|c|c|c|c|}
\hline & \begin{tabular}{|l} 
Adoption \\
rate
\end{tabular} & $\begin{array}{l}\text { Recent } \\
\text { growth }\end{array}$ & $\begin{array}{l}\text { Accelerat } \\
\text { ion }\end{array}$ & $\begin{array}{l}\text { Expected } \\
\text { growth }\end{array}$ \\
\hline Intercompany computer networks, including extranet and electronic data interchange (EDI) & $21.4 \%$ & $35 \%$ & $107 \%$ & $28 \%$ \\
\hline Automated products and parts identification (for example, bar coding or QR coding) & $21.3 \%$ & $40 \%$ & $141 \%$ & $40 \%$ \\
\hline Customer Relationship Management (CRM) software & $20.0 \%$ & $40 \%$ & $165 \%$ & $47 \%$ \\
\hline Warehouse management system (WMS) & $15.5 \%$ & $37 \%$ & $157 \%$ & $43 \%$ \\
\hline $\begin{array}{l}\text { Virtual product development or modelling software, including computer-aided design (CAD), } \\
\text { computer-aided engineering (CAE) and computer-aided manufacturing (CAM) }\end{array}$ & $15.3 \%$ & $22 \%$ & $82 \%$ & $15 \%$ \\
\hline Software as a service (SaaS) (for example, cloud computing - software) & $15.0 \%$ & $154 \%$ & $113 \%$ & $69 \%$ \\
\hline Software for demand forecasting or demand planning & $13.8 \%$ & $34 \%$ & $209 \%$ & $53 \%$ \\
\hline Executive dashboards for analytics or decision-making & $13.7 \%$ & $128 \%$ & $157 \%$ & $88 \%$ \\
\hline Live stream processing technology or real-time monitoring & $13.1 \%$ & $120 \%$ & $97 \%$ & $53 \%$ \\
\hline Wireless communications for production & $12.0 \%$ & $56 \%$ & $151 \%$ & $54 \%$ \\
\hline Enterprise Resource Planning (ERP) & $11.9 \%$ & $32 \%$ & $203 \%$ & $50 \%$ \\
\hline Infrastructure as a service (laaS) (for example, cloud computing - hardware) & $9.6 \%$ & $206 \%$ & $141 \%$ & $94 \%$ \\
\hline Global positioning system (GPS) (exclude personal use) & $9.6 \%$ & $60 \%$ & $86 \%$ & $32 \%$ \\
\hline Transportation management system & $9.1 \%$ & $42 \%$ & $159 \%$ & $47 \%$ \\
\hline Supply chain collaboration and visibility system & $8.7 \%$ & $43 \%$ & $165 \%$ & $49 \%$ \\
\hline Automated storage (AS) and retrieval system (RS) & $7.4 \%$ & $53 \%$ & $131 \%$ & $46 \%$ \\
\hline Software for large-scale data processing (for example, Hadoop) & $7.0 \%$ & $52 \%$ & $167 \%$ & $57 \%$ \\
\hline Waste technologies & $5.6 \%$ & $46 \%$ & $100 \%$ & $32 \%$ \\
\hline Mobile device with geolocation capabilities & $5.6 \%$ & $81 \%$ & $112 \%$ & $50 \%$ \\
\hline 4 to 9 axis computer numerically controlled (CNC) machinery & $5.3 \%$ & $33 \%$ & $92 \%$ & $23 \%$ \\
\hline Computer-integrated manufacturing (CIM) & $5.1 \%$ & $34 \%$ & $169 \%$ & $43 \%$ \\
\hline Software integration of quality results with planning and control softwares & $4.8 \%$ & $71 \%$ & $280 \%$ & $117 \%$ \\
\hline Air or emission technologies & $4.6 \%$ & $64 \%$ & $106 \%$ & $41 \%$ \\
\hline Radio frequency identification (RFID) & $4.6 \%$ & $28 \%$ & $310 \%$ & $67 \%$ \\
\hline Web or wireless sensors & $4.5 \%$ & $83 \%$ & $95 \%$ & $42 \%$ \\
\hline Manufacturing resource planning (MRP II) & $4.4 \%$ & $38 \%$ & $300 \%$ & $82 \%$ \\
\hline $\begin{array}{l}\text { Automated systems for inspection (for example, vision-based, laser-based, X-ray, high- } \\
\text { definition (HD) camera or sensor-based) }\end{array}$ & $4.3 \%$ & $52 \%$ & $173 \%$ & $60 \%$ \\
\hline Sensor network and integration & $3.4 \%$ & $70 \%$ & $179 \%$ & $74 \%$ \\
\hline Water technologies & $3.1 \%$ & $41 \%$ & $156 \%$ & $45 \%$ \\
\hline Geographic information systems (GIS) & $3.0 \%$ & $43 \%$ & $133 \%$ & $40 \%$ \\
\hline Lasers used in materials processing (including surface modification) & $2.8 \%$ & $40 \%$ & $125 \%$ & $36 \%$ \\
\hline Energy technologies (for example, ISO 50000) & $2.7 \%$ & $69 \%$ & $155 \%$ & $63 \%$ \\
\hline Bioproducts & $2.5 \%$ & NA & NA & NA \\
\hline Virtual manufacturing & $2.5 \%$ & $67 \%$ & $140 \%$ & $56 \%$ \\
\hline Manufacturing execution system (MES) & $2.3 \%$ & $35 \%$ & $367 \%$ & $96 \%$ \\
\hline Robot without sensing or vision systems & $2.2 \%$ & $47 \%$ & $129 \%$ & $41 \%$ \\
\hline Automated machinery for sorting, transporting or assembling parts & $2.1 \%$ & $40 \%$ & $233 \%$ & $67 \%$ \\
\hline Robot with sensing or vision systems & $1.8 \%$ & $100 \%$ & $189 \%$ & $94 \%$ \\
\hline Flexible manufacturing cell (FMC) or flexible manufacturing system (FMS) & $1.8 \%$ & $64 \%$ & $129 \%$ & $50 \%$ \\
\hline Remote sensing (RS) & $1.7 \%$ & $100 \%$ & $100 \%$ & $53 \%$ \\
\hline Additive manufacturing including rapid prototyping for plastics and 3D printing for plastics & $1.6 \%$ & $167 \%$ & $180 \%$ & $113 \%$ \\
\hline Spatial data infrastructure & $1.2 \%$ & $50 \%$ & $250 \%$ & $83 \%$ \\
\hline Biotechnology & $1.0 \%$ & $\mathrm{NA}$ & NA & NA \\
\hline Plasma sputtering & $1.0 \%$ & $67 \%$ & $100 \%$ & $40 \%$ \\
\hline Additive manufacturing including rapid prototyping for metals and 3D printing for metals & $0.8 \%$ & $75 \%$ & $500 \%$ & $188 \%$ \\
\hline Unmanned aerial system (for example, drone) & $0.7 \%$ & $250 \%$ & $240 \%$ & $171 \%$ \\
\hline $\begin{array}{l}\text { Additive manufacturing including rapid prototyping for materials other than plastics and } \\
\text { metals, and 3D printing other than plastics and metals }\end{array}$ & $0.6 \%$ & $40 \%$ & $450 \%$ & $150 \%$ \\
\hline Microelectromechanical system (MEMS) & $0.4 \%$ & $100 \%$ & $150 \%$ & $75 \%$ \\
\hline Micro-manufacturing (for example, micro-machining or micro-moulding) & $0.4 \%$ & $33 \%$ & $400 \%$ & $100 \%$ \\
\hline Nanotechnology & $0.3 \%$ & NA & NA & $\mathrm{NA}$ \\
\hline
\end{tabular}

Note: The recent growth is measured as the share of firms having adopted the technology for less than 3 years divided by the share of those having adopted the technology for more than 3 years. The acceleration is the share of firms planning to use the technology over the share of firms using the technology for more than 3 years. The Expected growth is the share of firms using the technology divided by the share of those who planned to use it.

Source: Calculations based on Statistics Canada, Survey of Advanced Technology tables.. 


\section{Annex 4. Technologies and practices with great co-occurrence}

Jaccard similarity coefficients, 30 largest pairings

\begin{tabular}{|c|c|c|}
\hline Technology or business practice $\mathrm{A}$ & Technology or business practice $B$ & $\begin{array}{l}\text { Jaccard coefficient } \\
\text { between } A \text { and } B\end{array}$ \\
\hline $\begin{array}{r}\text { Infrastructure as a service (laaS) (e.g., cloud computing } \\
\text { hardware) }\end{array}$ & $\begin{array}{r}\text { Software as a service (AaaS) (e.g., cloud computing } \\
\text { software) }\end{array}$ & 0.490 \\
\hline Mobile device with geolocation capabilities & Global positioning system (GPS) (exclude personal use) & 0.417 \\
\hline $\begin{array}{l}\text { Additive manufacturing including rapid prototyping for } \\
\text { materials other than plastics and metals, and 3D printing } \\
\text { other than plastics and metals }\end{array}$ & $\begin{array}{l}\text { Additive manufacturing including rapid prototyping for } \\
\text { metals and } 3 \mathrm{D} \text { printing for metals }\end{array}$ & 0.351 \\
\hline Waste technologies & Water technologies & 0.333 \\
\hline Warehouse Management System (WMS) & Software for demand forecasting or demand planning & 0.327 \\
\hline $\begin{array}{r}\text { Automated products and parts identification (e.g., bar or } \\
\text { QR coding) }\end{array}$ & Warehouse Management System (WMS) & 0.320 \\
\hline Robot(s) without sensing or vision systems & Robot(s) with sensing or vision systems & 0.308 \\
\hline Spatial data infrastructure & Remote sensing (RS) & 0.306 \\
\hline Supply chain collaboration and visibility systems & Warehouse Management System (WMS) & 0.302 \\
\hline Software for demand forecasting or demand planning & Customer Relationship Management (CRM) software & 0.297 \\
\hline Supply chain collaboration and visibility systems & Software for demand forecasting or demand planning & 0.296 \\
\hline Live stream processing technology or real-time monitoring & Software for large-scale data processing (e.g., Hadoop) & 0.293 \\
\hline Waste technologies & Air or emission technologies & 0.292 \\
\hline Mobile device with geolocation capabilities & Geographic information systems (GIS) & 0.292 \\
\hline Wireless communications for production & $\begin{array}{r}\text { Inter-company computer networks including Extranet and } \\
\text { electronic data interchange (EDI) }\end{array}$ & 0.290 \\
\hline Spatial data infrastructure & Geographic information systems (GIS) & 0.290 \\
\hline $\begin{array}{r}\text { Software as a service (AaaS) (e.g., cloud computing } \\
\text { software ) }\end{array}$ & Live stream processing technology or real-time monitoring & 0.278 \\
\hline Manufacturing Resource Planning (MRP II) & Manufacturing Execution System (MES) & 0.278 \\
\hline $\begin{array}{l}\text { Additive manufacturing including rapid prototyping for } \\
\text { metals and 3D printing for metals }\end{array}$ & $\begin{array}{r}\text { Additive manufacturing including rapid prototyping for } \\
\text { plastics and 3D printing for plastics }\end{array}$ & 0.275 \\
\hline Warehouse Management System (WMS) & Transportation management system & 0.274 \\
\hline $\begin{array}{r}\text { Automated products and parts identification (e.g., bar or } \\
\text { QR coding) }\end{array}$ & Software for demand forecasting or demand planning & 0.269 \\
\hline $\begin{array}{r}\text { Inter-company computer networks including Extranet and } \\
\text { electronic data interchange (EDI) }\end{array}$ & $\begin{array}{r}\text { Automated products and parts identification (e.g., bar or } \\
\text { QR coding) }\end{array}$ & 0.268 \\
\hline Supply chain collaboration and visibility systems & Transportation management system & 0.265 \\
\hline Executive dashboards for analytics or decision-making & Customer Relationship Management (CRM) software & 0.263 \\
\hline $\begin{array}{r}\text { Inter-company computer networks including Extranet and } \\
\text { electronic data interchange (EDI) }\end{array}$ & Enterprise Resource Planning (ERP) & 0.262 \\
\hline Quality Management System (QMS) & $\begin{array}{r}\text { Business certification or certification renewals (e.g., ISO } \\
9000, \text { ISO 14000) }\end{array}$ & 0.261 \\
\hline Executive dashboards for analytics or decision-making & Software for demand forecasting or demand planning & 0.258 \\
\hline Automated Storage (AS) and Retrieval System (RS) & Supply chain collaboration and visibility systems & 0.258 \\
\hline 4-9 axis computer numerically controlled (CNC) machinery & $\begin{array}{l}\text { Virtual Product Development or modelling software } \\
\text { including Computer Aided Design (CAD), Computer Aided } \\
\text { Engineering (CAE), Computer Aided Manufacturing (CAM) }\end{array}$ & 0.258 \\
\hline Remote sensing (RS) & Geographic information systems (GIS) & 0.257 \\
\hline
\end{tabular}

Note: Business practices are shown in italics. This table shows the 30 highest coefficients out of $2278(=68 \mathrm{x}$ $67 / 2$ ) unique pairs of technologies.

Source: OECD/Statistics Canada analysis of Statistics Canada's Survey of Advanced Technology. 


\section{Annex 5. Large firms' use of technologies compared to small firms}

\section{Share of large firms as a ratio of the share of small firms, by technology used}

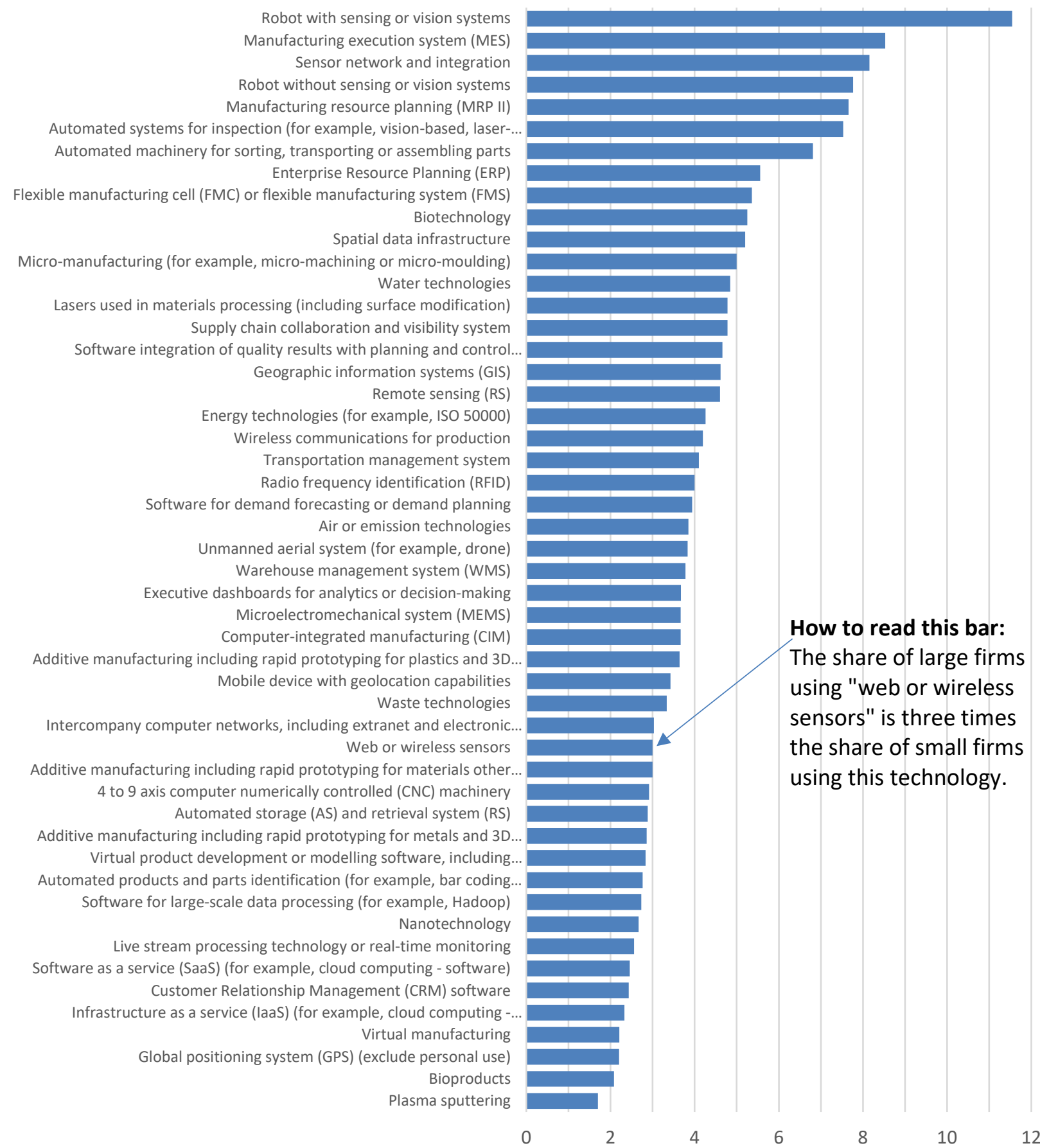

Source: Calculations based on Statistics Canada, Survey of Advanced Technology tables. 


\section{Annex 6. Industry characteristics based on regression-adjusted industry coefficients for factor loadings}

\section{Regression coefficients}

\begin{tabular}{|c|c|c|c|c|c|c|c|c|}
\hline \multicolumn{2}{|c|}{$\begin{array}{c}\text { Factor 1: } \\
\text { Logistics } \\
\text { software } \\
\text { technologies }\end{array}$} & $\begin{array}{c}\text { Factor 2: } \\
\text { Management } \\
\text { practices and } \\
\text { tools }\end{array}$ & $\begin{array}{l}\text { Factor 3: } \\
\text { Production } \\
\text { process } \\
\text { technologies }\end{array}$ & $\begin{array}{c}\text { Factor 4: } \\
\text { Geomatics } \\
\text { and } \\
\text { geospatial } \\
\text { technologies }\end{array}$ & $\begin{array}{l}\text { Factor 5: Bio- } \\
\text { and- } \\
\text { environmenta } \\
\text { I technologies }\end{array}$ & $\begin{array}{c}\text { Factor } 6 \text { : } \\
\text { Software and } \\
\text { infrastructure } \\
\text { as a service }\end{array}$ & $\begin{array}{c}\text { Factor } 7: \\
\text { Additive and } \\
\text { micro } \\
\text { manufacturin } \\
g \\
\text { technologies }\end{array}$ & $\begin{array}{l}\text { R\&D intensity } \\
\text { group }\end{array}$ \\
\hline 113-Forestry and logging & $-0.094^{* *}$ & $-0.061^{*}$ & $-0.076^{* \star *}$ & $0.25^{\star \star \star}$ & -0.027 & -0.025 & 0.008 & Low \\
\hline 211-Oil and gas extraction & $-0.077^{*}$ & $-0.075^{*}$ & $-0.076^{* * *}$ & $0.279^{\star \star *}$ & $0.068^{* *}$ & $0.23^{* * *}$ & 0.016 & Medium-low \\
\hline 212-Mining and quarrying (except oil and gas) & -0.021 & -0.034 & -0.033 & $0.237^{\star \star \star}$ & $0.058^{\star \star}$ & 0.054 & 0.014 & Medium-low \\
\hline 213-Support activities for mining, and oil and gas extraction & $-0.059^{*}$ & $-0.067^{* *}$ & $-0.073^{\star * *}$ & $0.159^{\star \star \star}$ & -0.037 & $0.053^{\star}$ & 0.01 & Medium-low \\
\hline 221-Utilities & 0.038 & 0.033 & $-0.092^{* * *}$ & $0.379^{* * *}$ & 0.005 & $0.135^{* * *}$ & 0.004 & Low \\
\hline 311-Food manufacturing (set to 0 ) & Set to 0 & Set to 0 & Set to 0 & Set to 0 & Set to 0 & Set to 0 & Set to 0 & Medium-low \\
\hline 312-Beverage and tobacco product & 0.011 & -0.035 & $-0.05^{*}$ & 0.038 & $0.05^{\star}$ & -0.031 & 0.008 & Medium-low \\
\hline 313-Textile mills & 0.03 & $0.067^{*}$ & -0.017 & -0.032 & -0.043 & -0.03 & 0.006 & Medium-low \\
\hline 314-Textile product mills & -0.015 & 0.017 & -0.011 & -0.002 & $-0.071^{* *}$ & -0.009 & 0.01 & Medium-low \\
\hline 315-Clothing & 0.01 & -0.052 & -0.012 & -0.023 & $-0.085^{\star \star *}$ & -0.051 & 0.006 & Medium-low \\
\hline 316-Leather and allied product & 0.005 & -0.007 & 0.02 & -0.017 & $-0.075^{*}$ & -0.006 & 0.011 & Medium-low \\
\hline 321-Wood product & -0.025 & $0.045^{*}$ & $0.073^{* * *}$ & $0.041^{* *}$ & $-0.043^{\star *}$ & -0.014 & 0.012 & Medium-low \\
\hline 322-Paper product & $0.054^{*}$ & $0.076^{\star \star}$ & $0.044^{*}$ & 0.027 & 0.02 & 0.003 & 0.006 & Medium-low \\
\hline 323-Printing and related support activities & 0.008 & -0.015 & -0.009 & -0.029 & -0.019 & 0.048 & 0.014 & Medium-low \\
\hline 324-Petroleum and coal product & 0.016 & $0.102^{*}$ & -0.01 & 0.068 & $0.097^{\star *}$ & -0.022 & 0.014 & Medium-low \\
\hline 325-Chemical manufacturing & $0.054^{* \star}$ & $0.127^{\star \star \star}$ & 0.007 & 0.023 & $0.04^{* *}$ & 0.009 & -0.007 & High/medium-high \\
\hline 326-Plastics and rubber products & 0.036 & $0.185^{\star \star \star}$ & $0.096^{\star \star *}$ & -0.02 & $-0.045^{*}$ & -0.036 & 0.015 & Medium \\
\hline 327-Non-metallic mineral product & -0.014 & 0.026 & 0.027 & $0.049^{*}$ & 0.026 & 0.026 & $0.021^{*}$ & Medium \\
\hline 331-Primary metal & -0.006 & $0.232^{\star \star \star}$ & $0.089^{* \star *}$ & -0.014 & $-0.04^{*}$ & -0.015 & $0.02^{*}$ & Medium \\
\hline 332-Fabricated metal product & -0.038 & $0.2^{\star \star *}$ & $0.117^{\star \star *}$ & -0.026 & -0.027 & -0.028 & $0.059^{\star \star \star}$ & Medium-low \\
\hline 333-Machinery & $-0.041^{*}$ & $0.239^{\star \star *}$ & $0.105^{\star \star \star}$ & $-0.039^{* *}$ & $-0.086^{\star \star *}$ & -0.03 & $0.043^{\star \star *}$ & Medium-high \\
\hline 334-Computer and electronic product & $0.052^{* *}$ & $0.265^{\star \star *}$ & $0.081^{* * *}$ & -0.019 & $-0.101^{\star \star *}$ & 0.027 & $0.051^{\star \star *}$ & High \\
\hline 335-Electrical equipment, appliance and component & 0.025 & $0.312^{* \star *}$ & $0.055^{\star *}$ & $-0.047^{*}$ & $-0.085^{\star \star \star}$ & $-0.069^{* *}$ & $0.034^{\star \star *}$ & Medium-high \\
\hline 336-Transportation equipment & -0.011 & $0.265^{\star \star \star}$ & $0.122^{\star * *}$ & $-0.049^{* \star *}$ & $-0.056^{\star \star \star}$ & $-0.07^{* * *}$ & $0.03^{\star \star *}$ & Medium-high \\
\hline 337 -Furniture and related product & -0.022 & $0.107^{\star \star *}$ & $0.098^{\star * *}$ & -0.034 & $-0.049^{\star \star}$ & -0.015 & $0.041^{* \star *}$ & Medium-low \\
\hline 339-Miscellaneous manufacturing & 0.024 & $0.123^{\star \star *}$ & $0.085^{* * *}$ & -0.025 & $-0.081^{\star \star \star *}$ & -0.008 & $0.055^{\star \star *}$ & NA \\
\hline 411-Farm product merchant wholesalers & 0.036 & $-0.102^{* * *}$ & -0.04 & 0.034 & $-0.047^{*}$ & $0.089^{* *}$ & 0.004 & Low \\
\hline 412-Petroleum (and products) merchant wholesalers & $0.102^{\star \star}$ & $-0.112^{* \star *}$ & $-0.085^{\star * *}$ & $0.135^{\star \star *}$ & $-0.056^{* *}$ & 0.001 & 0.009 & Low \\
\hline 413-Food, beverage and tobacco merchant wholesalers & $0.094^{\star \star \star}$ & $-0.085^{* *}$ & $-0.072^{* \star *}$ & 0.038 & $-0.041^{*}$ & -0.017 & 0.004 & Low \\
\hline 414-Personal and household goods merchant wholesalers & $0.219^{\star \star \star}$ & $-0.107^{\star * \star}$ & $-0.1^{\star * *}$ & -0.04 & $-0.109^{\star \star \star}$ & 0.053 & 0.011 & Low \\
\hline 415-Motor vehicle merchant wholesalers & $0.166^{\star \star \star}$ & $-0.109^{* * *}$ & $-0.083^{* * *}$ & 0.013 & $-0.099^{\star \star *}$ & $0.055^{\star}$ & $0.019^{*}$ & Low \\
\hline 416-Building material and supplies merchant wholesalers & $0.058^{*}$ & $-0.068^{* *}$ & $-0.049^{* *}$ & 0.01 & $-0.073^{* \star *}$ & 0.016 & $0.024^{\star *}$ & Low \\
\hline 417-Machinery, equip. and supplies merchant wholesalers & $0.111^{\star \star \star}$ & -0.031 & $-0.061^{* * *}$ & 0.03 & $-0.103^{\star \star \star}$ & $0.089^{* \star *}$ & $0.024^{\star \star}$ & Low \\
\hline 418-Miscellaneous merchant wholesalers & $0.103^{* \star \star}$ & -0.041 & $-0.082^{* * *}$ & $0.083^{* \star *}$ & -0.035 & 0.024 & 0.01 & Low \\
\hline 419-B-to-B electronic markets, and agents and brokers & 0.012 & $-0.111^{* \star *}$ & $-0.068^{\star \star *}$ & $0.058^{* *}$ & $-0.083^{\star \star *}$ & $0.082^{* *}$ & 0.01 & Low \\
\hline 441-Motor vehicle and parts dealers & 0.111 & -0.086 & $-0.102^{*}$ & -0.022 & 0.009 & $0.19^{\star * *}$ & 0.007 & Low \\
\hline 442-Furniture and home furnishings stores & 0.151 & -0.223 & $-0.222^{*}$ & 0.097 & 0.08 & -0.042 & 0.025 & Low \\
\hline 443-Electronics and appliance stores & 0.186 & -0.191 & -0.138 & 0.038 & -0.011 & 0.139 & 0.013 & Low \\
\hline 444-Building material and garden equip. and supplies dealers & $0.185^{\star}$ & 0.029 & -0.105 & 0.045 & -0.052 & 0.092 & 0.008 & Low \\
\hline 445-Food and beverage stores & 0.011 & $-0.188^{\star \star *}$ & $-0.08^{* *}$ & -0.028 & -0.036 & -0.043 & 0.013 & Low \\
\hline 446-Health and personal care stores & $0.157^{* \star}$ & $-0.165^{* * *}$ & -0.044 & -0.012 & -0.061 & -0.002 & 0.007 & Low \\
\hline 447-Gasoline stations & -0.044 & $-0.208^{* *}$ & -0.065 & -0.007 & -0.012 & -0.04 & 0.015 & Low \\
\hline 448-Clothing and clothing accessories stores & 0.081 & $-0.24^{* *}$ & $-0.175^{\star \star}$ & -0.074 & $-0.158^{\star \star}$ & $0.16^{*}$ & 0.011 & Low \\
\hline 451-Sporting goods, hobby, book and music stores & 0.02 & $-0.191^{\star \star *}$ & -0.072 & 0.003 & $-0.084^{*}$ & $0.144^{\star *}$ & 0.025 & Low \\
\hline 452-General merchandise stores & $0.225^{\star \star \star}$ & $-0.25^{\star \star *}$ & $-0.104^{* \star *}$ & -0.007 & -0.048 & -0.023 & 0.012 & Low \\
\hline 453-Miscellaneous store retailers & $0.111^{\star *}$ & $-0.152^{* * *}$ & $-0.071^{*}$ & 0.017 & $-0.087^{\star *}$ & -0.024 & 0.011 & Low \\
\hline 454-Non-store retailers & $0.219^{*}$ & $-0.183^{*}$ & $-0.167^{* *}$ & $0.138^{*}$ & $-0.153^{*}$ & 0.057 & 0.014 & Low \\
\hline 481-Air transportation & $0.107^{\star \star \star}$ & $-0.077^{* *}$ & $-0.105^{\star \star *}$ & $0.243^{\star \star \star}$ & -0.038 & 0.044 & $0.023^{*}$ & Low \\
\hline 482-Rail transportation & 0.055 & $-0.143^{*}$ & -0.077 & $0.24^{\star \star *}$ & -0.082 & 0.013 & 0.004 & Low \\
\hline 483-Water transportation & -0.039 & $-0.08^{*}$ & $-0.122^{\star \star *}$ & $0.231^{\star \star *}$ & 0.041 & $0.078^{*}$ & 0.014 & Low \\
\hline 484-Truck transportation & $0.088^{\star * \star}$ & $-0.157^{* \star *}$ & $-0.107^{* \star *}$ & $0.248^{\star \star *}$ & -0.032 & 0.018 & 0.01 & Low \\
\hline 485-Transit and ground passenger transportation & 0.026 & $-0.188^{* \star *}$ & $-0.091^{* * *}$ & $0.176^{\star \star *}$ & $-0.042^{*}$ & 0.047 & $0.02^{*}$ & Low \\
\hline 486-Pipeline transportation & 0.057 & 0 & -0.084 & $0.432^{\star \star *}$ & -0.018 & 0.129 & -0.004 & Low \\
\hline 487-Scenic and sightseeing transportation & $-0.075^{*}$ & $-0.137^{* \star *}$ & $-0.07^{* *}$ & $0.122^{\star \star \star}$ & $-0.057^{*}$ & $0.091^{*}$ & 0.013 & Low \\
\hline 488-Support activities for transportation & $0.078^{* *}$ & $-0.121^{* \star *}$ & $-0.088^{* * *}$ & $0.181^{* \star *}$ & -0.033 & 0.014 & 0.005 & Low \\
\hline 491-Postal service & 0.034 & $-0.184^{*}$ & -0.042 & 0.097 & -0.075 & 0.014 & 0.014 & Low \\
\hline 492-Couriers and messengers & $0.075^{\star}$ & $-0.096^{\star *}$ & $-0.064^{* *}$ & $0.23^{* \star \star}$ & -0.048 & $0.092^{\star *}$ & 0.007 & Low \\
\hline 493-Warehousing and storage & $0.224^{\star \star *}$ & $-0.077^{\star *}$ & $-0.09^{* * *}$ & $0.051^{*}$ & $-0.082^{\star \star *}$ & 0.018 & 0.005 & Low \\
\hline 541-Professional, scientific and technical services & $-0.077^{\star \star *}$ & -0.027 & $-0.077^{* * *}$ & $0.085^{* * *}$ & $-0.084^{\star \star *}$ & $0.197^{* \star *}$ & $0.02^{* * *}$ & Medium-low to High \\
\hline Intercept & $-0.084^{* \star *}$ & -0.007 & $0.021^{* *}$ & $-0.044^{* * *}$ & $0.041^{* * *}$ & $-0.059^{* * *}$ & $-0.017^{* * *}$ & \\
\hline Size fixed effect & Yes & Yes & Yes & Yes & Yes & Yes & Yes & \\
\hline Country of control fixed effect & Yes & Yes & Yes & Yes & Yes & Yes & Yes & \\
\hline Outsourcing fixed effect & Yes & Yes & Yes & Yes & Yes & Yes & Yes & \\
\hline $\mathrm{N}$ & 7912 & 7912 & 7912 & 7912 & 7912 & 7912 & 7912 & \\
\hline R2 & 0.24 & 0.38 & 0.21 & 0.19 & 0.07 & 0.08 & 0.04 & \\
\hline
\end{tabular}


Note: $* * *$ p-value $<=0.001 ; * *: 0.001<$ p-value $<=0.01 ; *: 0.01<$ p-value $<=0.05$. Food manufacturing is set to 0 to avoid collinearity. The darker is the green colour, the more positively significant is the industry fixed effect (relative to food manufacturing). The darker the red colour, the more negatively significant is the industry fixed effect (relative to food manufacturing). Industry fixed effects coloured in blank are not significantly different from the food manufacturing fixed effect. The last column provides the industry R\&D intensity group as defined in Galindo-Rueda and Verger (2016) after converting the taxonomy from ISIC to NAICS.

Source: OECD/Statistics Canada analysis of Statistics Canada's Survey of Advanced Technology.

\section{Industry cluster dendrogram based on regression coefficients}

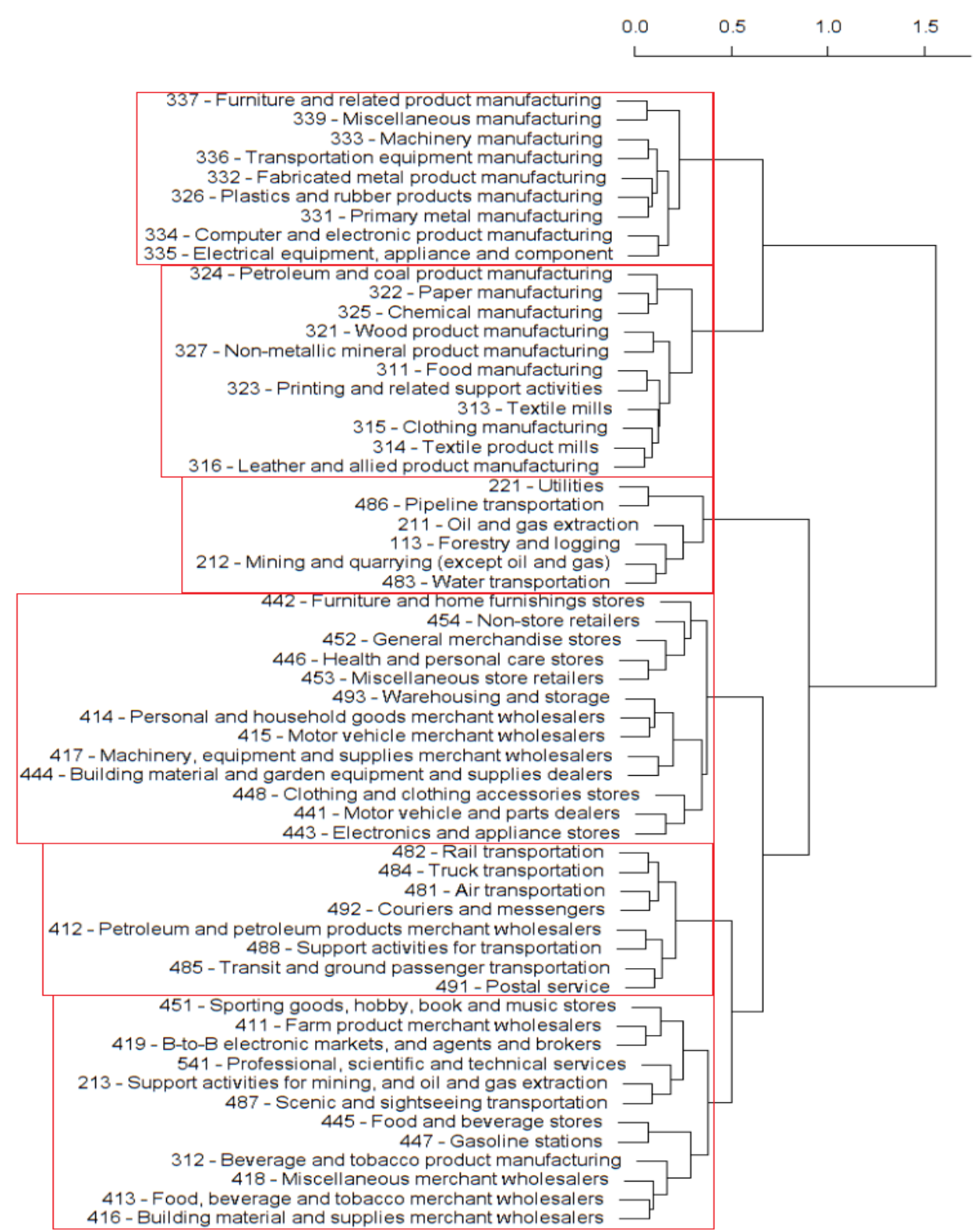

Note: Hierarchical cluster analysis based on Ward's method.

Source: OECD/Statistics Canada analysis of Statistics Canada's Survey of Advanced Technology. 